\title{
Viking Afterbody Heating Computations and Comparisons to Flight Data
}

\author{
Karl T. Edquist ${ }^{\dagger}$ \\ NASA Langley Research Center, Hampton, Virginia, 23681 \\ Michael J. Wright ${ }^{*}$ \\ NASA Ames Research Center, Moffett Field, CA 95050 \\ Gary A. Allen Jr." \\ ELORET Corporation, Moffett Field, CA 95050
}

\begin{abstract}
Computational fluid dynamics predictions of Viking Lander 1 entry vehicle afterbody heating are compared to flight data. The analysis includes a derivation of heat flux from temperature data at two base cover locations, as well as a discussion of available reconstructed entry trajectories. Based on the raw temperature-time history data, convective heat flux is derived to be $0.63-1.10 \mathrm{~W} / \mathrm{cm}^{2}$ for the aluminum base cover at the time of thermocouple failure. Peak heat flux at the fiberglass base cover thermocouple is estimated to be $0.54-0.76 \mathrm{~W} / \mathrm{cm}^{2}$, occurring 16 seconds after peak stagnation point heat flux. Navier-Stokes computational solutions are obtained with two separate codes using an 8species Mars gas model in chemical and thermal non-equilibrium. Flowfield solutions using local time-stepping did not result in converged heating at either thermocouple location. A global time-stepping approach improved the computational stability, but steady state heat flux was not reached for either base cover location. Both thermocouple locations lie within a separated flow region of the base cover that is likely unsteady. Heat flux computations averaged over the solution history are generally below the flight data and do not vary smoothly over time for both base cover locations. Possible reasons for the mismatch between flight data and flowfield solutions include underestimated conduction effects and limitations of the computational methods.
\end{abstract}

\section{Nomenclature}

DES Detached Eddy Simulation

GCSC Guidance Control and Sequencing Computer

$\mathrm{h} \quad$ altitude above reference ground level $(\mathrm{km})$

MSL Mars Science Laboratory

$\mathrm{p} \quad$ pressure $(\mathrm{Pa})$

q heat flux $\left(\mathrm{W} / \mathrm{cm}^{2}\right)$

$\mathrm{R}_{\mathrm{s}} \quad$ aeroshell shoulder radius of curvature (m)

$R_{n} \quad$ aeroshell nose radius of curvature (m)

$\mathrm{Re}_{\mathrm{D}} \quad$ Reynolds number based on aeroshell diameter, $\rho \mathrm{DD} / \mu$

RTG Radioisotope Thermoelectric Generator

T temperature (K)

TPS Thermal Protection System

$\mathrm{t} \quad$ GCSC time (sec)

\footnotetext{
${ }^{\dagger}$ Aerospace Engineer, Exploration Systems Analysis Branch, Mail Stop 489, AIAA Senior Member.

* Senior Research Scientist, Reacting Flow Environments Branch, Mail Stop 230-2, AIAA Senior Member.

+ Senior Research Scientist, Reacting Flow Environments Branch, Mail Stop 230-2. 


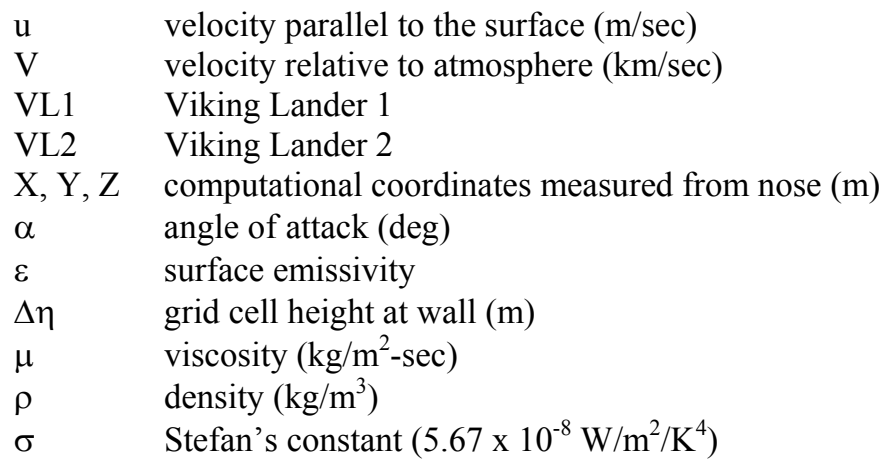

\section{Subscripts}

$\begin{array}{ll}\text { conv } & \text { convective } \\ \text { MA } & \text { Marvin-Akin formula } \\ \text { nose } & \text { forebody nose } \\ \text { SG } & \text { Sutton-Graves formula } \\ \text { w } & \text { wall condition } \\ \infty & \text { freestream condition }\end{array}$

\section{Introduction}

$\mathrm{T}$ he 1976 Viking missions represented the first successful U. S. landing on the surface of Mars. The Viking Lander 1 and 2 (VL1 and VL2) entry capsules entered from orbit at an atmosphere-relative velocity of $4.5 \mathrm{~km} / \mathrm{sec}^{1}$. Both entries utilized a rigid aeroshell, supersonic parachute, and powered terminal descent system to reach the Martian surface. Thermocouple gages were placed on each aeroshell afterbody, or base cover, to collect temperature data and validate predictions of heat flux during entry. Pre-flight estimates, including a factor of safety of 1.5 , predicted that backshell heat flux would be about $3 \%$ of the forebody nose laminar value ${ }^{1}$. Post-flight analysis of the temperature response showed that the heating rates were as high as $4.2 \%$ of the nose laminar heating level $^{1}$. Previous analysis suggested that the higher than expected heat flux may have been caused by turbulent transition $^{2}$, but no additional data exist to support that possibility. Recent computational fluid dynamics (CFD) analysis of the Mars Science Laboratory (MSL) predicted afterbody heat fluxes as high as 3\% (without a factor of safety) of the laminar forebody level for an aeroshell similar to Viking ${ }^{3}$.

The objective of this paper is to compare CFD afterbody computations to heat flux derived from Viking flight temperature data. Previous comparisons between CFD methods and Earth entry heat flux data showed promising results ${ }^{4}$. The current work is the first known documented effort to compare heating from modern CFD methods to Viking flight data ${ }^{4}$. Mars Pathfinder heat flux data also exist, but no effort has been made to measure CFD tools against the afterbody data. An analysis of the Viking flight data is presented along with Navier-Stokes solutions of the entry vehicle flowfield. The intended benefit is to validate the computational tools against flight data for blunt body wake flowfields and guide the determination of afterbody aeroheating uncertainties for future Mars entry vehicles. The current practice is to use relatively large afterbody aeroheating uncertainties (safety factor of 2-3) because of limited flight data for code validation and difficulty in predicting wake flowfields. Large uncertainties lead to added thermal protection system (TPS) material mass on the backshell, which can adversely affect aerodynamic stability and take away mass that could potentially be used elsewhere in the entry system. As entry system mass and performance increase for future missions, the need for lift requires flying at a non-zero angle of attack $(\alpha)$, which exposes the backshell to a potentially more severe heating environment. For example, a hypersonic trim $\alpha$ of $16 \mathrm{deg}$ has been considered for $\mathrm{MSL}^{5}$. Additional landed mass also requires more volume, which increases backshell TPS surface area and exposes the afterbody to more extreme conditions. Validation of computational tools using Viking flight data is an important step in understanding how much uncertainty is necessary for afterbody heating estimates and determining where computational improvements are needed. 


\section{Analysis}

The following sections describe the aeroshell geometry and thermocouple placement, the temperature flight data, a derivation of convective heat flux, and estimates for data uncertainties. Finally, the computational approach used to model the wake flowfield is described.

\section{A. Aeroshell Geometry and Base Cover Thermocouples}

Figure 1 shows the Viking entry vehicle aeroshell geometry. The entry vehicle was a 3.5-meter diameter 70deg sphere-cone forebody with a biconic afterbody ${ }^{3}$. The radial center of gravity was placed to achieve a hypersonic lift-to-drag ratio of 0.18 at nominal $\alpha$ of $-11.1 \mathrm{deg}^{1}$. The base cover was constructed of $0.0406 \mathrm{~cm}$ of laminated glass fabric and phenolic resin (fiberglass) for the inner cone, and $0.0254 \mathrm{~cm}$ of aluminum alloy for the outer cone ${ }^{6}$. No ablative thermal protection material existed on the backshell, presumably because the pre-flight estimate of heat flux was small ${ }^{1}\left(3 \%\right.$ of $24 \mathrm{~W} / \mathrm{cm}^{2}$ forebody stagnation point heat flux).

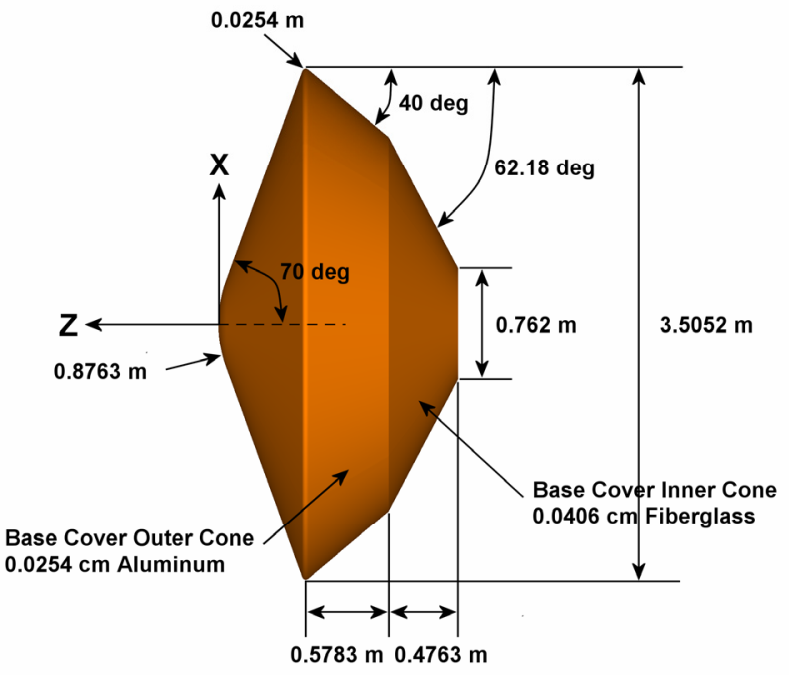

Figure 1. Viking Aeroshell Geometry in the Computational Coordinate System (Ref. 3)

Temperature gages were installed at two locations on the VL1 base cover to verify pre-flight predictions of afterbody heat flux. Thin-film gages were spot-welded to the aluminum and fiberglass base covers at the locations shown in Figure $2^{2}$. The thermocouple locations are accurate to within $+/-1$ inch radially and $+/-0.5$ inch circumferentially ${ }^{7}$. No information was found on the thermocouple performance characteristics, other than the thermocouples did not have identical specifications?

\section{B. Derivation of Convective Heat Flux from Temperature Data}

The VL1 temperature-time histories at both base cover locations are shown in Figure 3. The thermocouple on the aluminum cover started at a lower temperature than did the fiberglass thermocouple and experienced a more rapid

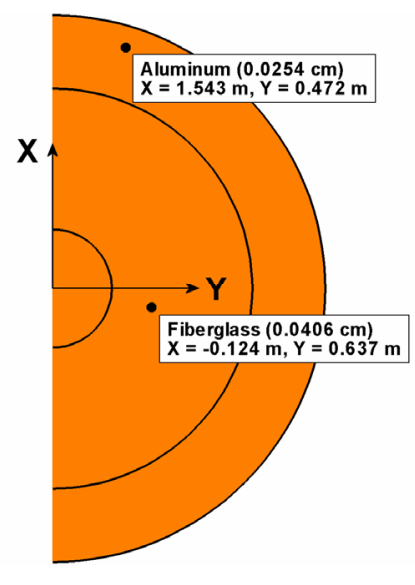

Figure 2. Location of Viking Base Cover Thermocouples in the Computational Coordinate System (Ref. 4)

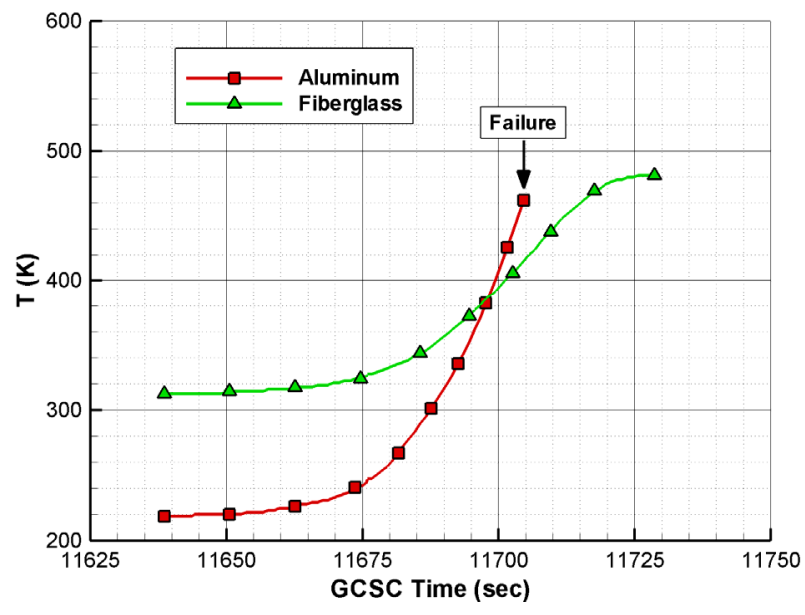

Figure 3. VL1 Base Cover Temperatures (Ref. 7) 
temperature increase during entry. The aluminum thermocouple failed during VL1 entry near 11703 sec based on the Guidance Control and Sequencing Computer (GCSC) time, but useful data was collected prior to that time. The aluminum base cover had not yet reached its peak temperature when the sensor failed. The thermocouple on the fiberglass cover operated successfully through the entire entry.

The author made an unsuccessful attempt to find the post-flight analysis of the VL1 backshell temperature and predictions for VL2 mentioned in Reference 8. That analysis showed that the VL1 fiberglass base cover temperature exceeded pre-flight estimates based on $3 \%$ of the stagnation point heat flux ${ }^{1}$. Table 1 recreates the base cover temperature predictions and flight data from Reference 1. Both thermocouples reached higher temperatures than expected, but they were still below the worst-case estimates. Figure 4 shows a previous analysis ${ }^{2}$ of normalized VL1 base cover heat flux as a function of freestream Reynolds number based on aeroshell diameter $\left(\operatorname{Re}_{\mathrm{D}}\right)$. The laminar nose heat flux was used as the normalizing parameter and was estimated using the Marvin-Akin formula? An abrupt increase in heating rate occurred at a $\operatorname{Re}_{\mathrm{D}}$ near $0.6 \times 10^{6}$ and was attributed to possible turbulent transition. Analysis in a later section proposes other possible causes for the heat flux slope increase. The peak heat flux from Reference 2 is as high as $5 \%$ of the laminar nose heating, which is slightly higher than the estimate from Reference 1.

Table 1. VL1 Peak Base Cover Temperatures (Ref. 1)

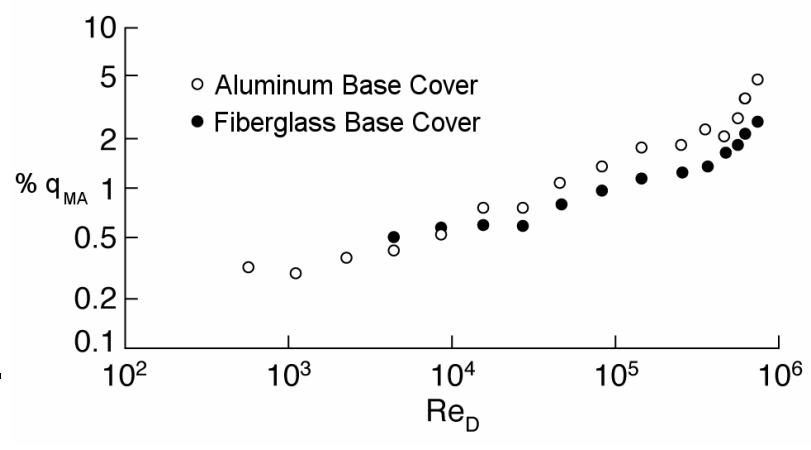

Figure 4. VL1 Base Cover Heat Flux Normalized by Marvin-Akin Heat Flux (Ref. 2)

The current analysis extends the work from Reference 2 to include estimates of material response, internal heat source uncertainties, and conduction effects for the purpose of validating CFD methods. The base cover temperature data used in the Reference 2 analysis were obtained as a function of GCSC time and used to derive heat flux based on the one-dimensional heat balance at each thermocouple location ${ }^{7}$. That heat balance can be written as the following equation:

$$
q_{\text {conv }}+q_{\text {int }}-q_{\text {rad }}+q_{\text {cond }}=\rho c_{p} s(\Delta T / \Delta t)
$$

The terms are defined as:

$\mathrm{q}_{\text {conv }}$ : external convective heat flux

$\mathrm{q}_{\text {int }}$ : internal heat source

$\mathrm{q}_{\mathrm{rad}}$ : outward radiated heat flux $=\sigma \varepsilon \mathrm{T}^{4}$

$\mathrm{q}_{\text {cond }}$ : conduction effects

$\rho$ : aeroshell skin density

$\mathrm{c}_{\mathrm{p}}$ : aeroshell skin specific heat

s: aeroshell skin thickness

$\Delta \mathrm{T} / \Delta \mathrm{t}$ : time rate-of-change of temperature

Solving for the convective heat flux gives the following equation:

$$
q_{c o n v}=\rho c_{p} s(\Delta T / \Delta t)+\sigma \varepsilon T^{4}-q_{\text {int }}-q_{\text {cond }}
$$


The first term dominates the heat flux calculation for the majority of the entry trajectory. A second-order finitedifference approximation of the flight data was used to calculate the temperature-time slope. A range of material properties for the aluminum and fiberglass was used to represent a range of possible material responses. The exact density, specific heats, and emissivities for the aluminum and fiberglass were not found, so representative nominal values were taken from standard materials ${ }^{10}$.

Two Radioisotope Thermoelectric Generator (RTG) units provided the primary internal heat source ${ }^{11}$. One unit was located on each side of the lander to provide power during ground operations (Fig. 5). The RTG's were located close to the second base cover cone and were shielded by wind covers ${ }^{6}$. The proximity of the RTG's may explain why the fiberglass thermocouple started at a higher temperature than did the aluminum cover. Each unit contained a plutonium oxide heat source with a nominal thermal output of $675 \mathrm{~W}$, for a total of $1350 \mathrm{~W}^{11}$. The heating contribution for the purpose of deriving convective heat flux was estimated to be $0.025 \mathrm{~W} / \mathrm{cm}^{2}$. This value is equal to the total heat output $(1350 \mathrm{~W})$ divided by the surface area of the second base cover cone $\left(53,400 \mathrm{~cm}^{2}\right)$. Since no specific information on the RTG operation during entry was found, that estimate for the heat output was used for the current analysis. The analysis in Reference 2 used $0.010 \mathrm{~W} / \mathrm{cm}^{2}$ for the RTG heat output ${ }^{7}$, which is approximately equal to the total heat output $(1350 \mathrm{~W})$ divided by the total base cover surface area $\left(126,500 \mathrm{~cm}^{2}\right)$. An uncertainty for the RTG heat output is also included in the results.

A rigorous analysis of the conduction effects was not performed due to unknown details of the base cover structure. The thermocouples were reportedly installed midway between rib stiffeners, which would minimize conduction losses ${ }^{7}$. However, attempts to find aeroshell drawings with the thermocouples were unsuccessful. Figure 6 shows the base cover ribs, which were located about every 9 deg of circumferential angle. However, additional information that would help make an estimate of conduction effects is not possible. Conduction would be expected to have more of an effect on the aluminum cover due to its higher thermal conductivity. Estimates for all material response uncertainty sources, including conduction effects, are presented in a later section.

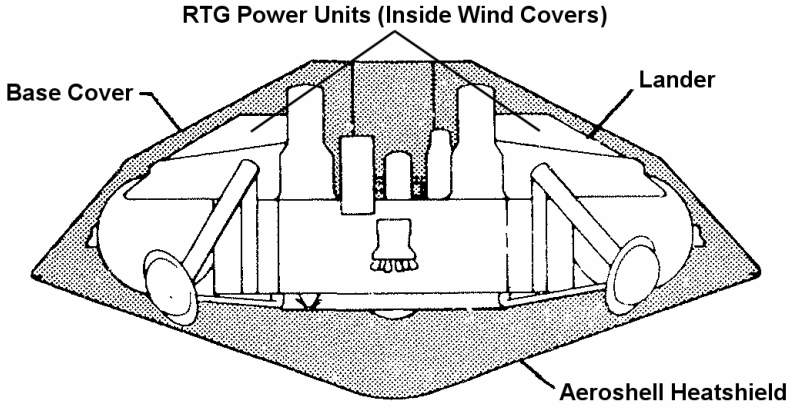

Figure 5. Viking Entry Vehicle and Lander (Ref. 6)

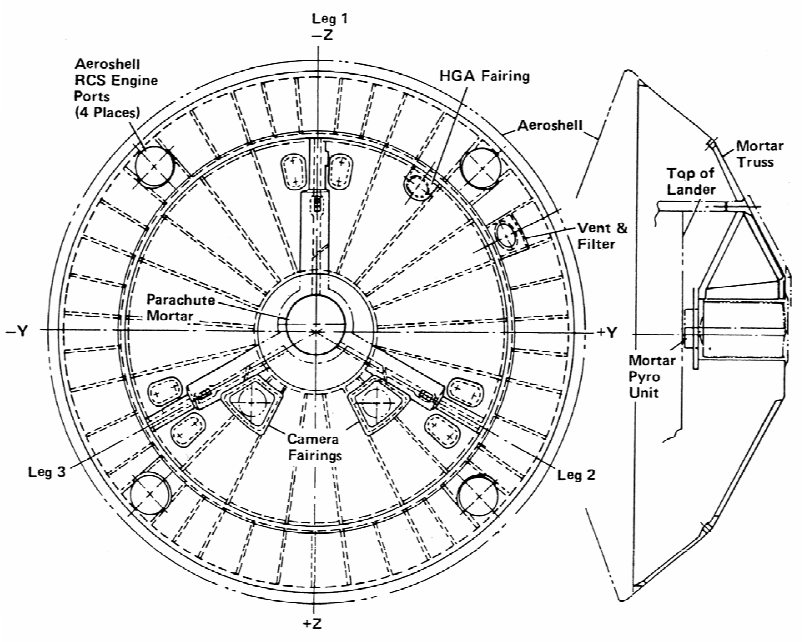

Figure 6. Viking Base Cover (Ref. 6)

\section{VL1 Entry Trajectory}

Freestream velocity, density, and temperature are required input for the computational tools used to predict the wake flowfield and base cover heat flux. Several efforts ${ }^{12-17}$ have been made to reconstruct the Mars atmosphere (density and temperature vs. altitude) and Viking entry trajectories (velocity vs. altitude). The atmospheric density profile can be reconstructed from on-board accelerometers and knowledge of the entry capsule's aerodynamic characteristics. Seiff and Kirk produced the seminal work on constructing a Martian atmospheric model derived from flight telemetry ${ }^{12}$. Blanchard used measured accelerations and pressure to obtain the entry trajectory independent of assumed aerodynamic characteristics ${ }^{13}$. For the purposes of this analysis, the post-flight VL1 entry 
trajectory as predicted using the Lander Trajectory and Atmospheric Reconstruction Program ${ }^{18}$ (LTARP) was used for specifying freestream conditions as a function of time. The LTARP trajectory was used in part because the data was available as a function of GCSC time, as was the base cover thermocouple data. Having the trajectory and thermocouple data both as a function of time made it easier to synchronize the computational predictions with the flight data.

Hardcopies of the LTARP VL1 trajectories ${ }^{7}$ were digitized to extract freestream conditions for the CFD solutions. The original assumptions that went into the LTARP trajectory are unknown e. g. entry vehicle aerodynamics and mass. In order to provide a check of the LTARP results, a new trajectory analysis for this paper was also performed with the TRAJ ${ }^{19}$ tool. The following section describes the TRAJ analysis and assumptions using the best available data.

\section{TRAJ Trajectory Analysis}

Any attempt at reconstructing the Viking 1 trajectory must start from the atmospheric model derived from the VL1 trajectory described in Seiff and Kirk's paper ${ }^{12}$. Unfortunately, the paper did not specify many of the critical parameters used in constructing their atmospheric model, e.g. entry vehicle mass and dimensions, entry vector, aerodynamics, etc. Only the atmospheric model and referenced planet ellipsoid from Reference 12 are useful towards reconstructing the VL1 trajectory. Fortunately, Seiff did provide a trajectory listing in microfiche to the National Space Science Data Center ${ }^{14}$. Other references must be used for finding the omitted parameters.

The VL1 aeroshell total mass at separation from the orbiter was $1056.9 \mathrm{~kg}$ and the propellant mass expended to deorbit the aeroshell was $71.6 \mathrm{~kg}^{1}$. During the coast period after the deorbit burn, the autopilot established a pitchover rate by using its reaction control system (RCS) to maintain a constant $\alpha$ of $20 \mathrm{deg}$. The aeroshell maintained this angle until 6 minutes before reaching the entry interface, at which time the autopilot adjusted the pitch-over rate to maintain a constant $\alpha$ of $-11.1 \mathrm{deg}^{15}$. When the inertial measurement unit detected $0.05 \mathrm{~g}$ deceleration, the autopilot stopped maintaining a constant $\alpha$ and allowed the vehicle to drift to its natural trim angle. The vehicle followed damped sinusoidal attitude until it reached its trim $\alpha$. The actual trim angle is difficult to determine from the telemetry data (the raw data is not self consistent). The pre-flight estimated trim $\alpha$ was $-11.1 \mathrm{deg}$. Based upon knowledge of consumed propellant, the entry mass at atmospheric interface for the VL1 aeroshell was $983.9 \mathrm{~kg}$.

The entry interface for VL1 was arbitrarily defined as an altitude of $243.84 \mathrm{~km}(800,000 \mathrm{ft} .)^{6}$. Unfortunately, the various published entry vectors are not consistent:

From Reference 1:

Inertial velocity: $4.61 \mathrm{~km} / \mathrm{sec}$

Inertial entry angle: $-16.97 \mathrm{deg}$

Aerographic latitude: $12.53 \mathrm{deg}$

Aerographic east longitude: $-62.11 \mathrm{deg}$

From Reference 6:

Inertial velocity: $4.61 \mathrm{~km} / \mathrm{sec}$

Inertial entry angle: $-16.99 \mathrm{deg}$

Aerographic latitude: $12.78 \mathrm{deg}$

Aerographic east longitude: $-62.15 \mathrm{deg}$

From Reference 13:

Relative velocity: $4.42 \mathrm{~km} / \mathrm{sec}$

Relative entry angle: $-17.63 \mathrm{deg}$

Inertial velocity: $4.62 \mathrm{~km} / \mathrm{sec}$

Inertial entry angle: $-16.85 \mathrm{deg}$ 
The entry vector that reproduces Seiff's trajectory from Reference 14 is the most believable solution because the VL1 atmospheric model was derived from that trajectory. The actual entry vector for VL1 was not provided in Reference 14, but an entry vector was deduced from a computer listing of the trajectory. New simulated trajectories for VL1 were iteratively generated using TRAJ. The entry velocity and position vectors were adjusted until the velocity and position vectors matched Seiff's trajectory at $126.05 \mathrm{sec}$ after entry. This approach provided a good overall match between the two trajectories. The last position vector listed in Seiff's trajectory was at $218 \mathrm{sec}$ after entry at an altitude of $26.88 \mathrm{~km}$, areocentric latitude of $21.0 \mathrm{deg}$, and longitude of $-49.87 \mathrm{deg}$. The position vector for TRAJ $218 \mathrm{sec}$ after entry was an altitude at $26.98 \mathrm{~km}$, areocentric latitude at $20.94 \mathrm{deg}$. and longitude at -49.91 deg.

The resultant TRAJ entry vector matches the data from Reference 14 and shows excellent agreement with the results from Reference 1:

Entry altitude: $241.48 \mathrm{~km}$

Inertial velocity: $4.60 \mathrm{~km} / \mathrm{sec}$

Inertial entry angle: $-17.01 \mathrm{deg}$

Inertial azimuth angle: $54.17 \mathrm{deg}$

Aerographic latitude: $12.67 \mathrm{deg}$

Aerographic east longitude: $-62.07 \mathrm{deg}$

An important parameter that a VL1 trajectory should reproduce is the time from atmospheric entry to parachute deployment, i.e. $429 \mathrm{sec}$. Parachute deployment was supposed to occur when the radar altimeter sensed an altitude of $19000 \mathrm{ft}$. However, parachute deployment actually occurred for VL1 at an altitude of $5.87441 \mathrm{~km}(19273 \mathrm{ft})^{1}$. TRAJ was programmed to deploy the parachute at the same altitude. The average trim angle of attack was adjusted until the time from atmospheric entry to parachute deployment was $429 \mathrm{sec}$. The resultant angle of attack fixed at $164.2 \mathrm{sec}$ after entry was $-10.25 \mathrm{deg}$. The ultimate measure of the VL1 trajectory simulation is the landing location. The actual landing location was aerographic latitude $22.46 \mathrm{deg}$ (aerocentric latitude $22.22 \mathrm{deg}$ ) and longitude -48.01 $\operatorname{deg}^{6}$. TRAJ simulated parachute deployment but also made the simplifying assumption that the lander remained attached to the parachute until surface impact. The TRAJ calculated landing location was aerocentric latitude 22.20 deg. and longitude $-47.82 \mathrm{deg}$.

Figure 7 compares the original LTARP trajectory with the current TRAJ analysis. For a given velocity, the LTARP altitude is up to $2 \mathrm{~km}$ lower than the TRAJ altitude. Density and velocity are shown in Figure 8 as a function of time because they primarily govern the aeroheating environment. LTARP's lower altitude results in a $11 \%$ lower density at a GCSC time of $11700 \mathrm{sec}$. Based on the relatively small differences in the velocity and density variations with time between the TRAJ and LTARP results, the LTARP trajectory was used for the CFD analysis.

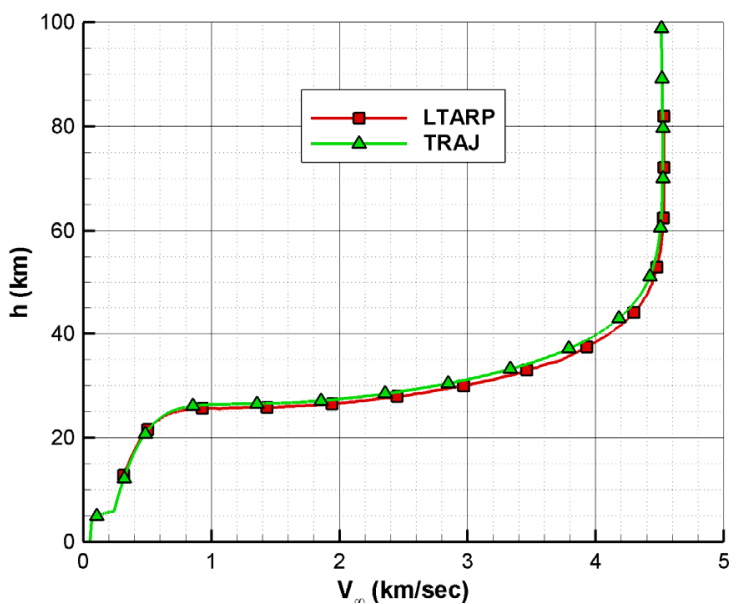

Figure 7. VL1 Altitude and Velocity from LTARP and TRAJ

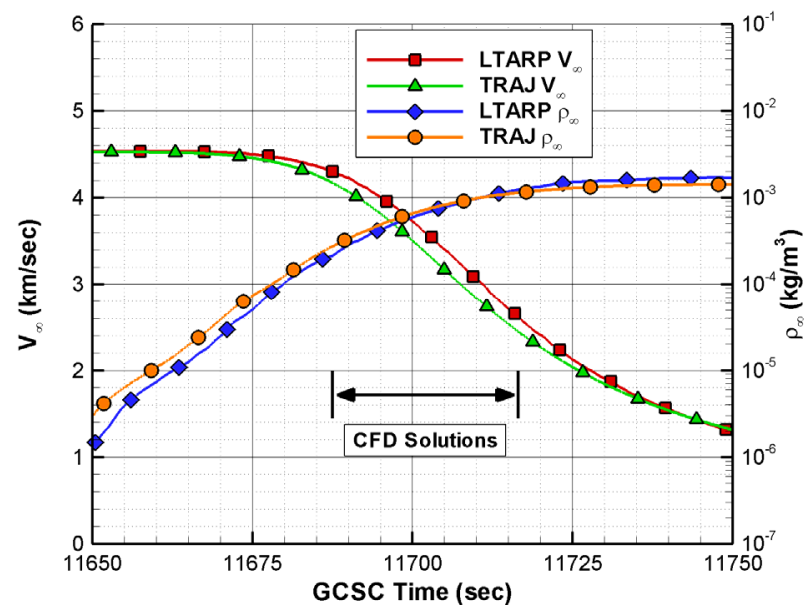

Figure 8. VL1 Velocity and Density from LTARP and TRAJ 
Figure 9 shows that the LTARP $\alpha$ is generally within 1 deg of the target value of $-11.1 \mathrm{deg}$. It is unknown how the angle of attack estimate was made, but a comparison with Reference 12 shows that the LTARP angle matches closely to onboard accelerometer measurements. Sutton-Graves convective heat flux ${ }^{20}$, dynamic pressure, and $\operatorname{Re}_{\mathrm{D}}$ are shown in Figure 10. The Sutton-Graves formula is for a sphere with the same radius of curvature as the Viking forebody nose $(0.8763 \mathrm{~m})$. The effective radius of curvature for the sphere-cone heatshield is larger, so the SuttonGraves estimate slightly overpredicts the heat flux near $24 \mathrm{~W} / \mathrm{cm}^{2}$ encountered during flight ${ }^{1}$. The peak stagnation point heat flux occurs at $11691.5 \mathrm{sec}$ GCSC time, followed by peak dynamic pressure at $11708 \mathrm{sec}$ and peak $\operatorname{Re}_{\mathrm{D}}$ at $11716.5 \mathrm{sec}$. Previous analysis from Reference 3 for the MSL aeroshell showed that afterbody heat flux reaches its peak between the dynamic pressure and $\mathrm{Re}_{\mathrm{D}}$ peaks. Computational solutions were obtained at the freestream conditions shown in Table 2. Temperature was taken from Reference 13 as a function of altitude. A positive $\alpha$ was specified in the computational solutions.

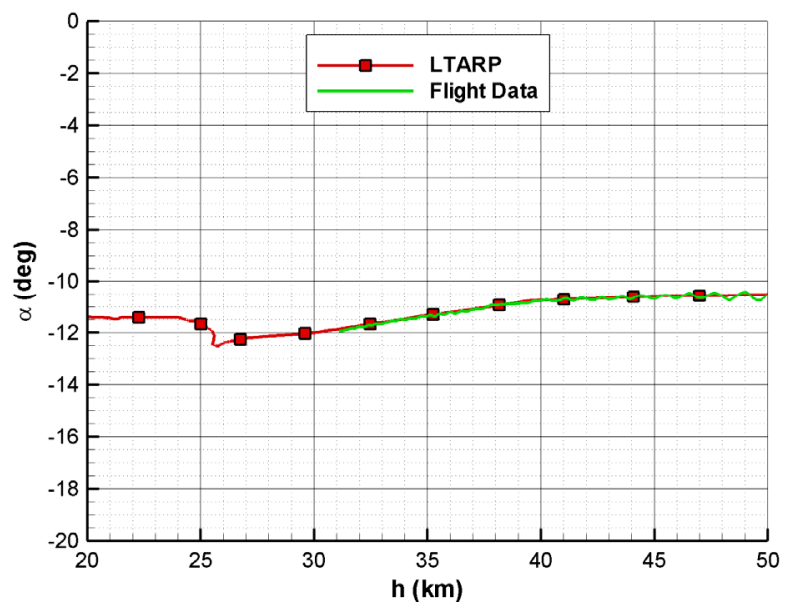

Figure 9. VL1 Angle of Attack from LTARP and Flight Data

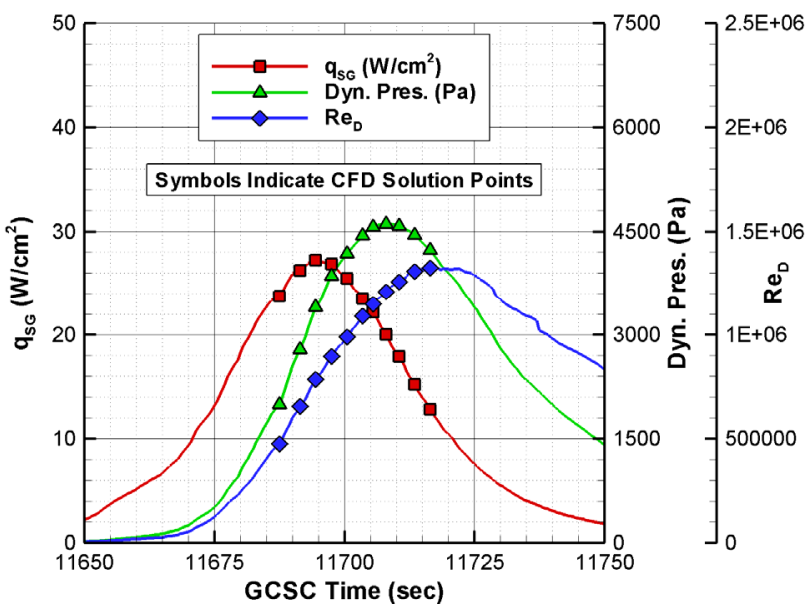

Figure 10. LTARP VL1 Sutton-Graves Heat Flux, Dynamic Pressure, and Reynolds Number

Table 2. LTARP VL1 Freestream Conditions for CFD Solutions

\begin{tabular}{cccccccc}
\hline \hline $\mathrm{t}(\mathrm{sec})$ & $\mathrm{h}(\mathrm{km})$ & $\mathrm{V}_{\infty}(\mathrm{km} / \mathrm{sec})$ & $\rho_{\infty}\left(\mathrm{kg} / \mathrm{m}^{3}\right)$ & $\mathrm{T}_{\infty}(\mathrm{K})$ & $\mathrm{M}_{\infty}$ & $\mathrm{Re}_{\mathrm{D}} \times 10^{-6}$ & $\alpha(\mathrm{deg})$ \\
\hline 11687.5 & 44.1 & 4.30 & $2.15 \times 10^{-4}$ & 139.2 & 22.2 & 0.474 & 10.61 \\
11691.5 & 41.0 & 4.16 & $3.22 \times 10^{-4}$ & 145.0 & 21.2 & 0.654 & 10.71 \\
11694.5 & 38.9 & 4.03 & $4.18 \times 10^{-4}$ & 151.5 & 20.0 & 0.785 & 10.85 \\
11697.5 & 36.7 & 3.88 & $5.12 \times 10^{-4}$ & 155.9 & 18.9 & 0.896 & 11.12 \\
11700.5 & 34.7 & 3.70 & $6.10 \times 10^{-4}$ & 160.0 & 17.8 & 0.990 & 11.37 \\
11703.5 & 33.3 & 3.50 & $7.24 \times 10^{-4}$ & 162.9 & 16.7 & 1.090 & 11.57 \\
11705.5 & 32.2 & 3.38 & $8.00 \times 10^{-4}$ & 164.7 & 16.1 & 1.147 & 11.70 \\
11708.0 & 31.2 & 3.20 & $8.97 \times 10^{-4}$ & 166.3 & 15.2 & 1.207 & 11.84 \\
11710.5 & 30.3 & 3.03 & $9.94 \times 10^{-4}$ & 167.9 & 14.3 & 1.255 & 11.97 \\
11713.5 & 29.3 & 2.81 & $1.12 \times 10^{-3}$ & 168.9 & 13.2 & 1.306 & 12.06 \\
11716.5 & 28.5 & 2.62 & $1.24 \times 10^{-3}$ & 170.4 & 12.2 & 1.323 & 12.11 \\
\hline \hline
\end{tabular}

\section{Computational Approach}

Navier-Stokes solutions of the VL1 entry vehicle flowfield were obtained using two different CFD codes. Primary solutions were obtained using the Langley Aerothermodynamic Upwind Relaxation Algorithm (LAURA) ${ }^{21}$. Additional solutions were obtained using the Data Parallel Line Relaxation (DPLR) ${ }^{22}$ code. The physical models within LAURA and DPLR are similar. Past comparisons between the codes for forebody laminar and turbulent heat flux on 70-deg sphere-cone geometries have shown good agreement ${ }^{23}$. 


\section{LAURA CFD Code}

LAURA has been used extensively to predict the aeroheating environments for Mars applications, including afterbody predictions ${ }^{24-26}$. For Mars flight conditions, LAURA models an 8-species Mars gas $\left(\mathrm{CO}_{2}, \mathrm{CO}, \mathrm{N}_{2}, \mathrm{O}_{2}\right.$, $\mathrm{NO}, \mathrm{C}, \mathrm{N}, \mathrm{O})$ in chemical and thermal non-equilibrium using the Park- $94^{27}$ reaction rates. A finite-volume approach is used to solve the full Navier-Stokes flowfield equations for all calculations presented here. The code uses Roe's averaging ${ }^{28}$ for the inviscid fluxes with second-order corrections using Yee's symmetric total variation diminishing (TVD) scheme ${ }^{29}$.

LAURA possesses the capability to adapt the computational mesh to the boundary layer and bow shock through user-defined parameters. Proper mesh resolution at the wall is especially important for reliable heating predictions. In LAURA, a user-specified cell Reynolds number controls the grid spacing at the wall:

$$
\operatorname{Re}_{w}=\left(\frac{\rho a \Delta \eta}{\mu}\right)_{w}
$$

Experience has shown that reliable laminar heating predictions can be achieved with $\mathrm{Re}_{\mathrm{w}}=\mathrm{O}(1)$. Grid adaptations are executed throughout the solution process until further adaptations do not significantly change the heat flux.

A super-catalytic wall boundary condition was implemented in all solutions, fixing the mass fractions for $\mathrm{CO}_{2}$ and $\mathrm{N}_{2}$ at their freestream values of 0.97 and 0.03 , respectively. This boundary condition results in conservative heating predictions in flight. A radiative-equilibrium wall temperature was specified to satisfy the following relation:

$$
q_{w}=\varepsilon \sigma T_{w}^{4}
$$

A fixed surface emissivity $(\varepsilon)$ of 0.89 was used for all solutions. The wall is assumed to radiate to a temperature of absolute zero. All heating results reported here are convective only and neglect the radiative heating contribution, which is expected to be small.

LAURA solutions were obtained on a singularity-free structured volume grid built with GridGen ${ }^{30}$. The forebody nose cap and afterbody base meshes do not have a singularity pole boundary that could otherwise introduce artificial discontinuities into the flowfield. Pitch plane symmetry allows modeling of only half of the aeroshell, so the effects of non-zero yaw angle were not examined. A grid resolution study examined meshes with finer resolution in all three coordinate directions.

\section{DPLR CFD Code}

DPLR solutions were run with essentially the same models and boundary conditions as were run with LAURA. DPLR is a parallel multi-block finite-volume code that solves the reacting Navier-Stokes equations including finiterate chemistry and the effects of thermal non-equilibrium using the same species set as LAURA. The Euler fluxes are computed using a modified (low-dissipation) form of Steger-Warming flux vector splitting ${ }^{31}$ with third-order spatial accuracy obtained via MUSCL extrapolation coupled with a minmod limiter ${ }^{32}$. Viscous fluxes are computed to second-order accuracy using a central difference approach. A supercatalytic wall boundary condition was employed with a surface emissivity of 0.89 for compatibility with the LAURA solutions. DPLR has been used previously for Earth entry afterbody heating simulations ${ }^{33,34}$.

Computational grids for the DPLR cases were generated by hyperbolically extruding a smooth singularity-free surface mesh. The outer boundary for each case was tailored to the bow shock location, and the wall spacing was chosen to ensure that the $\mathrm{Re}_{\mathrm{w}} \leq 1$. The nominal grid consisted of 8 blocks with 120 cells in the normal direction and 25,000 points on the body surface. The resulting volume grid had a total of just over 3 million cells. 


\section{E. Sources of Uncertainty}

A rigorous treatment of uncertainties is beyond the scope of this analysis. However, an estimate was made to account for uncertainties in the derivation of heat flux from temperature data. The following sections also discuss uncertainties associated with the entry trajectory and computational methods.

\section{Material Response, Internal Heat Source, and Conduction Uncertainties}

Uncertainties for all terms on the right hand side of Equation 2 are shown in Table 3. The uncertainties were combined to give low and high estimates for heat flux. A material response uncertainty is included to account for the lack of knowledge about the exact material properties of the aluminum and fiberglass base covers. Values for density and heat capacity were taken from representative materials 9 . A low estimate for convective heat flux results from low values for $\rho c_{p}$ and $\varepsilon$, a high value for $q_{\text {int }}$, and conduction effects included. The converse is true for a high heat flux calculation. The uncertainty in the RTG heat output was implemented as a $+/-100 \%$ variation in the nominal output of $0.025 \mathrm{~W} / \mathrm{cm}^{2}$. This heating contribution ended up being a small fraction of the total convective heat flux for the majority of the heat pulse. Conduction would be expected to affect the aluminum cover temperature more than the fiberglass temperature due to its much higher thermal conductivity. The effects of conduction were represented as a convective heat flux reduction of $25 \%$ for the aluminum and 5\% for the fiberglass. A reduction in heat flux was used since conduction through the aeroshell structure would lead to higher temperatures at the thermocouple locations that were not due to external convective heat flux. The variation in the aluminum and fiberglass base cover heat flux data are shown as low and high estimates in a later section.

\section{Trajectory Uncertainties}

Trajectory uncertainties arise from uncertainties in the entry system (aerodynamics, mass, navigation) and atmosphere (density) that result in a probabilistic distribution of entry paths. For design purposes, a statistical analysis is often employed to select the worst-case heating environments for TPS design purposes. In lieu of having the uncertainty information for the LTARP trajectory, the TRAJ analysis is intended to represent trajectory uncertainties for the VL1 entry.

Figure 11 shows an estimate for stagnation point heat flux using the Sutton-Graves formula with the LTARP and TRAJ freestream conditions. The peak heat flux from the LTARP trajectory is about $7 \%$ higher than the peak from the TRAJ trajectory. Computed afterbody heat fluxes on the two trajectories would be expected to differ by approximately the same amount. This difference is small compared to the overall uncertainty in the CFD heat flux predictions, so no additional cases were run on the TRAJ trajectory. 


\section{Computational Uncertainties}

A rigorous analysis of the afterbody heating sensitivities to computational model formulation (numerical, physical, and chemical) is beyond the scope of this paper. See Reference 35 for a discussion of the primary sources of uncertainty for Mars laminar heating predictions. In the current analysis, LAURA and DPLR were executed using the best available models for simulating chemically-reacting hypersonic flowfields in the Mars atmosphere. Standard boundary condition choices were made as they would be for flight vehicle aeroheating environments predictions, such as a super-catalytic wall condition and radiative-equilibrium wall temperature. The heat flux estimates assume a non-ablating surface, which is considered appropriate for VL1 given that the forebody heat flux was low and no ablative TPS material existed on the backshell.

Much of the computational uncertainty is related to the grid topology and refinement at the aeroshell shoulder. Previous experience with a similar aeroshell geometry showed that at least one cell per 7 deg of turning angle was needed for grid independent afterbody heat flux predictions ${ }^{3}$. The Viking aeroshells had a much smaller shoulder radius than did the geometry modeled in Reference 3, so an even tighter grid spacing requirement was expected. A grid resolution study was conducted to examine effects of grid refinement in the streamwise and surface-normal directions. Other sources of computational uncertainty were not examined.

\section{Results}

The base cover temperature-time history data were converted to heat flux using Equation 2. Uncertainties for the material properties, internal heat source, and conduction effects from Table 2 were included in the heat flux estimates. Comparisons of Navier-Stokes computations and the derived heat flux at both base cover locations are shown for the LTARP VL1 entry trajectory using LAURA and DPLR.

\section{A. Convective Heat Flux Derived from Temperature Data}

Figure 12 shows the aluminum base cover convective heat flux derived from the raw temperature as a function of time. The nominal heat flux matches the estimate from Reference 2. Possible causes for the noisy data include flow unsteadiness and thermocouple performance. Upper and lower data bounds are due to uncertainties in material properties, the RTG heat output, and conduction effects. The heat flux for the aluminum base cover thermocouple is $0.63-1.10 \mathrm{~W} / \mathrm{cm}^{2}$ at the time thermocouple failure occurred $(11704.5 \mathrm{sec})$. The variation due to the estimated uncertainties at $11704.5 \mathrm{sec}$ is $+0.13 /-0.34 \mathrm{~W} / \mathrm{cm}^{2}$ around the nominal value of $0.97 \mathrm{~W} / \mathrm{cm}^{2}$. The data bounds are asymmetric because conduction effects are only included in the lower heat flux estimate.

Figure 13 shows the same results for the fiberglass thermocouple location. Reference 2 data are between the nominal and low estimates. The derived heat flux exhibits even more noise that do the aluminum data. Peak heat flux is predicted to be $0.54-0.76 \mathrm{~W} / \mathrm{cm}^{2}$ at a time of $11710.5 \mathrm{sec}$, which is approximately $16 \mathrm{sec}$ after peak stagnation point heat flux and $2.5 \mathrm{sec}$ after peak dynamic pressure. This result is consistent with the analysis in

Reference 3, which showed that maximum afterbody heat flux for an aeroshell similar to Viking using CFD methods occurs near the time of peak dynamic pressure. Including all uncertainty estimates and conduction effects, the variation in peak heat flux is $+0.10 /-0.12 \mathrm{~W} / \mathrm{cm}^{2}$ about the nominal value of $0.66 \mathrm{~W} / \mathrm{cm}^{2}$.

A five point moving average was used to smooth the data before making comparisons to the CFD flowfield computations. The smoothed data are shown in Figures 14 and 15 for the aluminum and fiberglass base covers, respectively. At $11702.5 \mathrm{sec}$, the aluminum heat flux is $0.60-1.04 \mathrm{~W} / \mathrm{cm}^{2}$ with a nominal value of $0.92 \mathrm{~W} / \mathrm{cm}^{2}$. For the fiberglass base cover, the peak heat flux is $0.49-0.70 \mathrm{~W} / \mathrm{cm}^{2}$ with a nominal value of $0.61 \mathrm{~W} / \mathrm{cm}^{2}$.

Reference 6 reports that the VL2 aluminum base cover peak heat flux was $0.9 \mathrm{BTU} / \mathrm{ft}^{2}$-sec $\left(1.02 \mathrm{~W} / \mathrm{cm}^{2}\right)$ based on temperature data at the same location as the VL1 thermocouple. The assumptions governing that analysis are not known. The VL1 and VL2 entries were very similar and resulted in stagnation point heat fluxes that were within 3\% of one another ${ }^{6}$. The assumption is that, had the aluminum base cover thermocouple survived the entire VL1 entry, the data would have shown the peak heat flux to be close to the VL2 value. The current analysis estimates the VL1 peak nominal heat flux to be at least $0.97 \mathrm{~W} / \mathrm{cm}^{2}$. The aluminum thermocouple failed approximately $6 \mathrm{sec}$ prior to 
the time of peak fiberglass base cover temperature. Extrapolation of the nominal VL1 aluminum heat flux past the time of thermocouple failure would likely lead to a peak value near that of VL2.

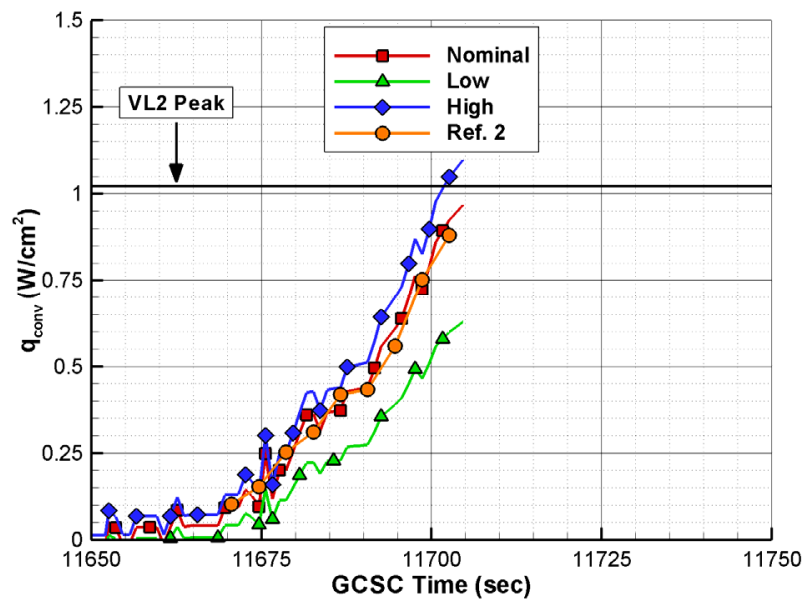

Figure 12. VL1 Aluminum Base Cover Convective Heat Flux Derived from Temperature Data (Raw Data)

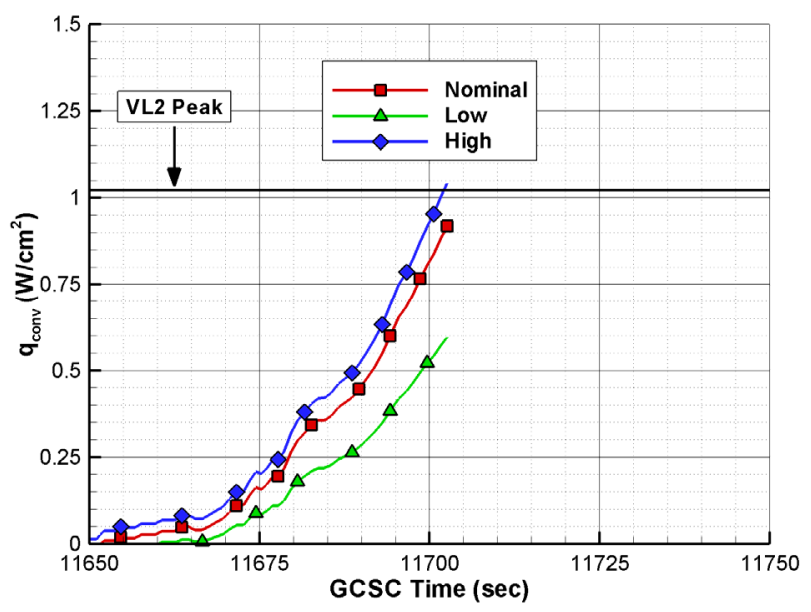

Figure 14. VL1 Aluminum Base Cover Convective Heat Flux Derived from Temperature Data (Smoothed Data)

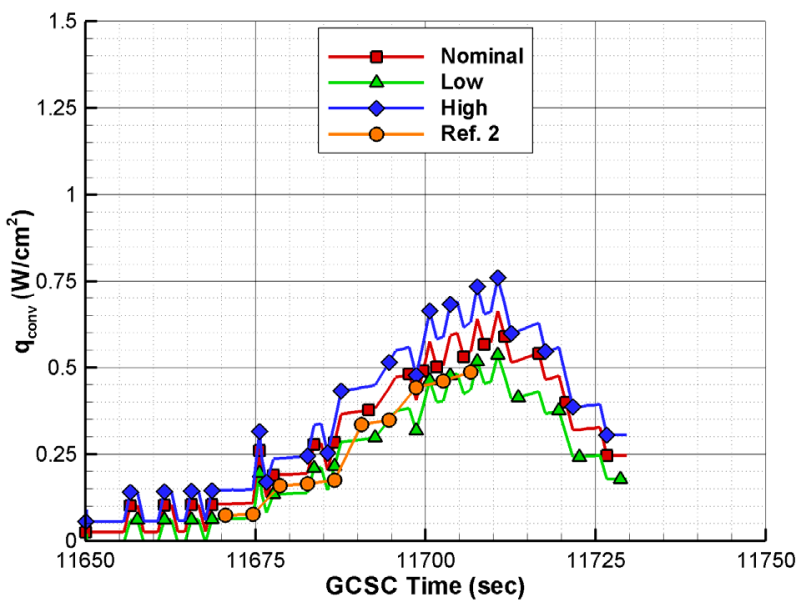

Figure 13. VL1 Fiberglass Base Cover Convective Heat Flux Derived from Temperature Data (Raw Data)

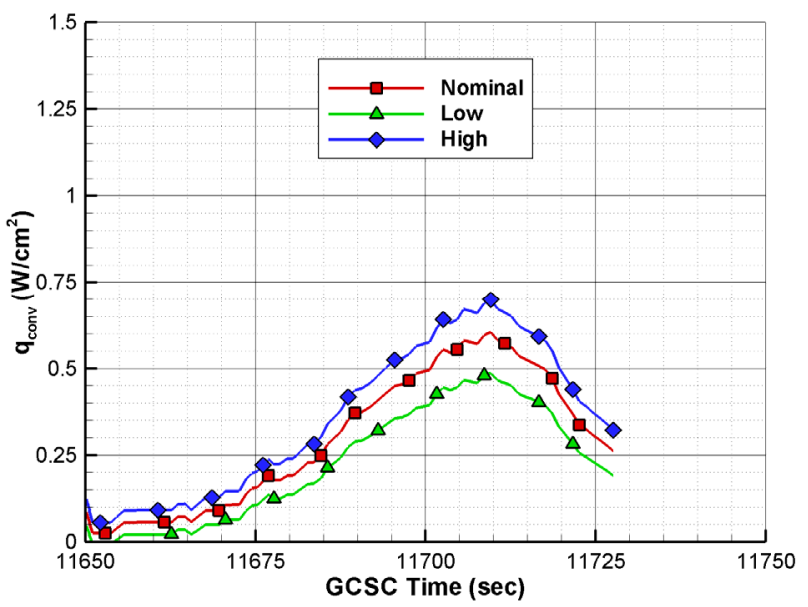

Figure 15. VL1 Fiberglass Base Cover Convective Heat Flux Derived from Temperature Data (Smoothed Data)

The design limit for Viking afterbody heat flux was estimated to be only $0.57 \mathrm{~W} / \mathrm{cm}^{2}$, which is well below the post-flight estimate of $1.02 \mathrm{~W} / \mathrm{cm}^{2}$ for VL2 ${ }^{6}$. The author believes that the base cover heat flux was underestimated because it was based on the stagnation point heat pulse. Reference 3 showed that afterbody heat flux for an aeroshell similar to Viking continues to rise after peak stagnation point heat flux and reaches a peak near the time of maximum dynamic pressure. Figure 16 shows that the nominal heat fluxes for both base cover locations mirror the dynamic pressure pulse. Thus, simply using the stagnation point heat pulse to shape the afterbody heat pulse would have missed the peak afterbody heating conditions.

The timing of the stagnation point heat pulse and afterbody heat pulse may explain the slope change in the normalized heat flux curve (Fig. 4) near a Reynolds number of $0.6 \times 10^{6}$. Previous analysis attributed the slope increase to possible turbulent transition ${ }^{2}$. The Reynolds number (as calculated in Ref. 3) where the slope changes corresponds to the time at which stagnation point heat flux reaches a maximum, but afterbody heat flux is still rising. 
Plotting the normalized heat flux, with stagnation point heat flux in the denominator, would cause a slope increase since stagnation point heat flux is decreasing and afterbody heat flux is still increasing at $\operatorname{Re}_{\mathrm{D}}=0.6 \times 10^{6}$. Figure 15 shows that the base cover heat fluxes mirror the dynamic pressure pulse and are still rising after stagnation point heat flux has peaked. Figure 17 shows an updated version of Figure 4 using the current derivation of base cover heat flux, the Sutton-Graves stagnation point heating estimate, and an updated Reynolds number calculation. Again, the afterbody heat flux normalized by the Sutton-Graves formula shows a similar slope change at a Reynolds number of $0.6 \times 10^{6}$. This does not necessarily mean that the slope change is not due to turbulent transition, but rather that other explanations are possible. Laminar CFD solutions for the Mars Pathfinder and Mars Exploration Rover wake flowfields produce the same slope change as the Viking data suggests, but those results have not been published.
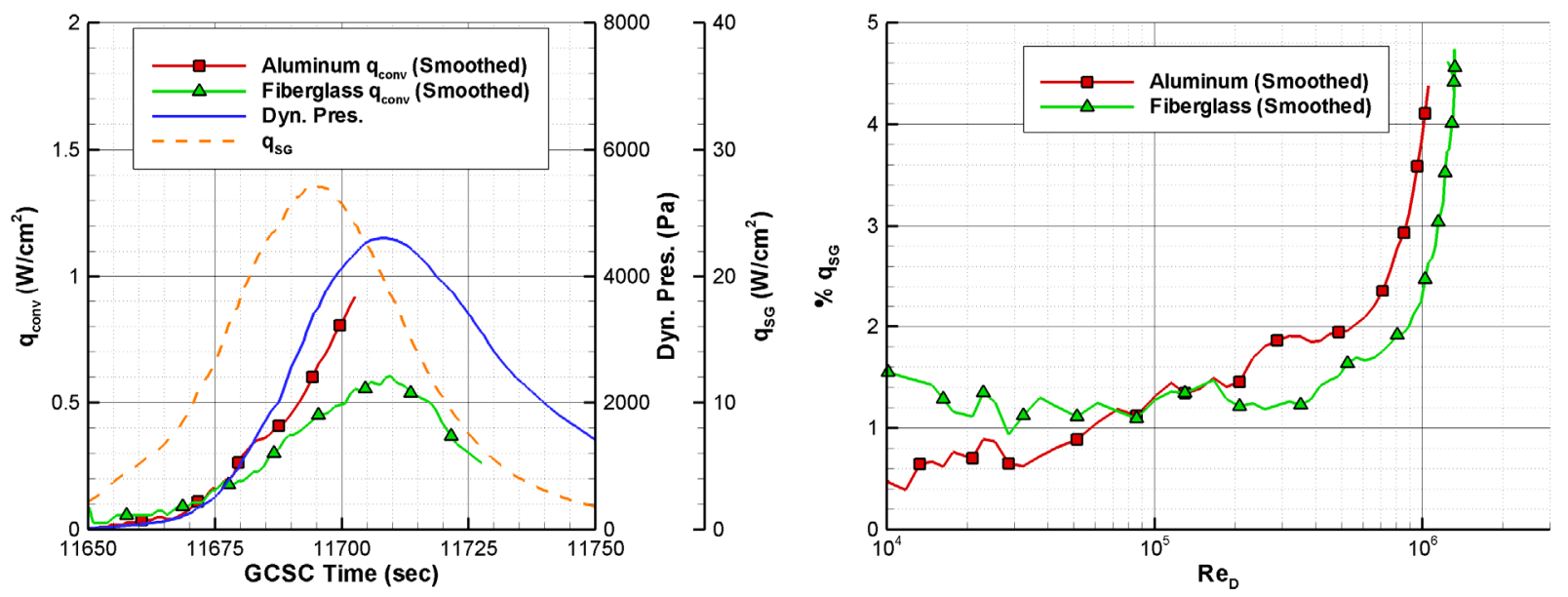

\section{Figure 16. VL1 Base Cover Nominal Convective Heat Figure 17. VL1 Base Cover Nominal Convective Heat Flux (Smoothed Data), Dynamic Pressure, and Sutton- Graves Heat Flux \\ Flux as a Percentage of Sutton-Graves Heat Flux (Smoothed Data)}

It is unlikely that the raw flight data noise (Fig. 12 and 13) is completely due to unsteady flow. Fluctuations may also be the result of thermocouple response characteristics. Measured base cover pressure data from Reference 1 does not indicate similar noise resulting from an unsteady flowfield. The only anomalous behavior observed was a drop in pressure shortly after peak stagnation point heating. The decrease in base pressure was attributed to the effects of ablation and outgassing on wake composition ${ }^{1}$.

\section{B. Comparisons of Computed Convective Heat Flux with Flight Data}

LAURA and DPLR laminar full-body solutions were obtained along the VL1 entry trajectory at the time points in Table 3. The computed heat flux was based on the radiative-equilibrium wall temperature condition and surface recombination of $\mathrm{CO}_{2}$ and $\mathrm{N}_{2}$ to their freestream mass fractions. Symmetry was enforced across the pitch plane, so any effects of non-zero yaw were not investigated. Accelerometer measurements showed that yaw angles were at most 1 deg during entry ${ }^{1}$. A grid resolution study was performed to determine a computational grid that resulted in grid-independent heat flux. Finally, LAURA and DPLR heating computations are compared to the heat flux data.

\section{LAURA Grid Resolution Study}

Reference 2 presents a grid resolution study for an MSL entry vehicle that is very similar to Viking. The results showed that a grid with one streamwise cell per $7 \mathrm{deg}$ of turning angle at the shoulder gave grid independent heat flux on the first afterbody cone. The ratio of the MSL shoulder radius to nose radius was 0.1 , whereas the Viking ratio was 0.029 . It was expected that the smaller Viking shoulder radius would require tighter streamwise spacing at the shoulder. Therefore, Viking solutions were initiated with essentially the same grid topology as the MSL baseline $\operatorname{grid}^{2}$. 
In order to produce reliable afterbody heating estimates, the computational grid must capture the flowfield features shown in Figure 18. The shear layer emanating from the shoulder is perhaps the most important flow feature since it influences the extent of the wake and vortical structures near the surface. It is critical to capture the shear layer with sufficient streamwise and normal grid points so that the effects are properly captured further downstream.

A grid resolution study patterned after the one from Reference 2 was conducted for the Viking analysis. The grid resolution study consisted of running several LAURA solutions near the time of peak fiberglass base cover heat flux as derived from the temperature data $(11710.5 \mathrm{sec})$. Beginning with the baseline grid, the mesh distribution was resolved to finer levels in all directions until the peak afterbody

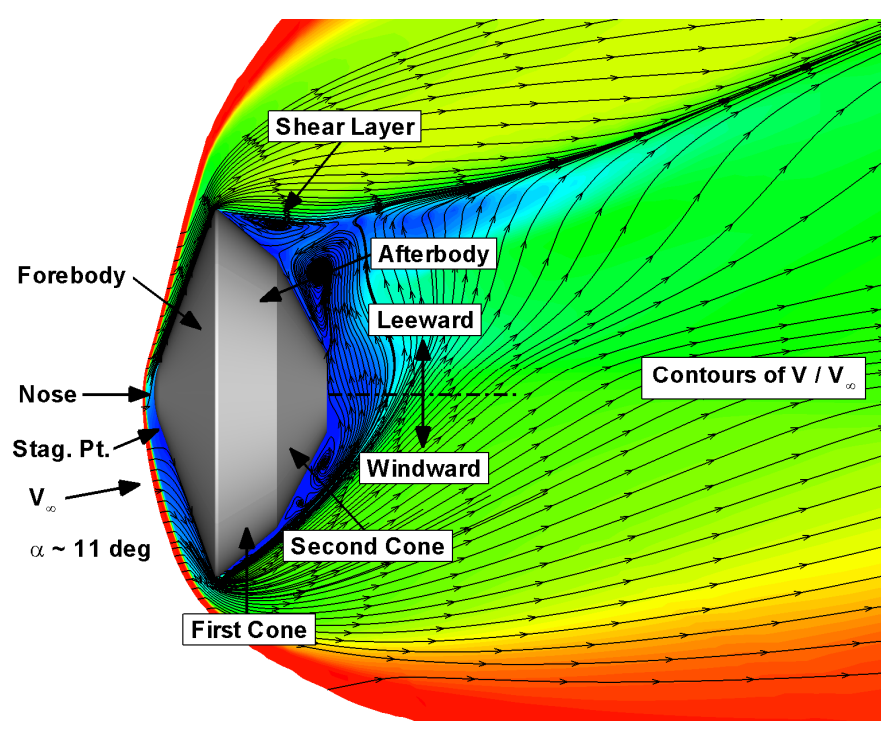

Figure 18. Viking Wake Flowfield heating rate remain unchanged with further grid refinement. Solutions at the remaining trajectory times used the same mesh resulting from the grid resolution study. A full grid resolution study was not performed for each trajectory point.

Table 4 summarizes the grids used in the refinement study, beginning with the baseline mesh (Grid 1). The surface mesh for Grid 1 is shown in Figure 19, showing relatively coarse streamwise spacing at the shoulder. Each subsequent grid possesses additional cells in the streamwise, circumferential, and/or normal direction for at least a portion of the grid. All grids were adapted to the boundary layer and bow shock within LAURA using the $\operatorname{Re}_{\mathrm{w}}$ specified in Table 4. The average streamwise resolution around the aeroshell shoulder is shown for each grid.

Table 4. LAURA Grid Resolution Study

\begin{tabular}{ccccccc}
\hline \hline \multirow{2}{*}{ Grid } & $\begin{array}{c}\text { Surface } \\
\text { Cells }\end{array}$ & $\begin{array}{c}\text { Normal } \\
\text { Cells }\end{array}$ & $\begin{array}{c}\text { Volume } \\
\text { Cells }\end{array}$ & $\mathrm{Re}_{\mathrm{w}}$ & $\begin{array}{c}\text { Avg. Deg./Cell } \\
\text { at Shoulder }\end{array}$ & Modification to Baseline Grid \\
\hline 1 & 6144 & 64 & 393,216 & 1 & 8.5 & Baseline \\
$1 \mathrm{a}$ & 6144 & 128 & 786,432 & 0.5 & 8.5 & 2x Normal \\
2 & 11,264 & 64 & 720,896 & 1 & 4.8 & 2x Streamwise \\
$2 \mathrm{a}$ & 11,264 & 128 & $1,441,792$ & 0.5 & 4.8 & 2x Streamwise and 2x Normal \\
3 & 17,664 & 64 & $1,130,496$ & 1 & 3.0 & 4x Streamwise \\
\hline \hline
\end{tabular}

Results from the grid resolution study are shown in Figure 20. Initially, the solutions were run with local timestepping i. e. the solutions were not run time-accurate. Using this approach, none of the grids in Table 4 gave steady state converged laminar heat flux predictions on the afterbody. Grids 1 and 1a predicted higher heat flux on the first afterbody windward cone compared to all other grids. Subsequent adaptations did not cause the solution to settle in the unsteady areas, even for the finest streamwise grid resolution.

The grid resolution study from Reference 2 did not display the same type of unsteady flow behavior for similar grid topologies using local time-stepping. The indication is

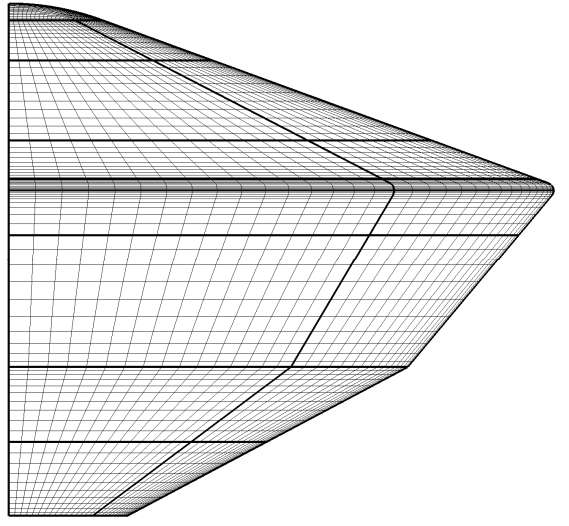

Figure 19. Surface Mesh for Grids 1 and 1a 
that the Viking flowfield is more likely to be unsteady, possibly due to a sharper shoulder radius than was modeled for MSL in Reference 2. The flight heat flux data show noise that may the result of flow unsteadiness, but it is difficult to isolate the reasons for the fluctuations.

Figures 21-23 show further results for Grid 3 at $t=11710.5 \mathrm{sec}$ using local time-stepping. Successive grid adaptations did not improve the convergence of the afterbody solution. Figure 21 shows three adapted grid solutions with a converged forebody flowfield. The heat flux on the first windward cone is fairly stable, but the remaining base cover areas are not. Figure 22 shows the iteration histories of pressure and heat flux, respectively, for the forebody nose and two base cover thermocouple locations. A converged forebody solution is indicated by the converged nose pressure and heat flux. The base cover pressures and heat fluxes fluctuate fairly significantly. Figure 23 shows the base cover histories on an expanded scale. Unsteadiness in the flowfield solutions at both results in large pressure and heat fluctuations using local time-stepping.

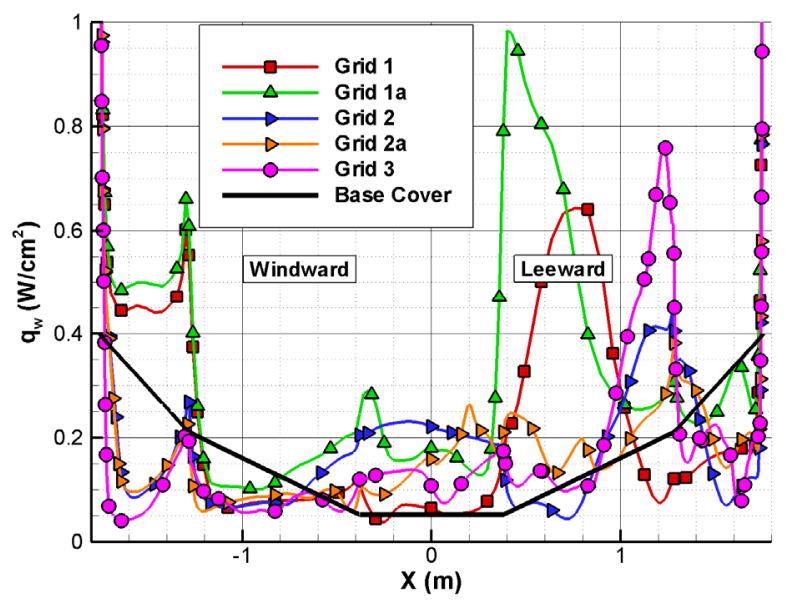

Figure 20. LAURA Afterbody Symmetry Plane Heat Flux at $\mathrm{t}=\mathbf{1 1 7 1 0 . 5} \mathrm{sec}$ for Various Grids with Local Time-Stepping

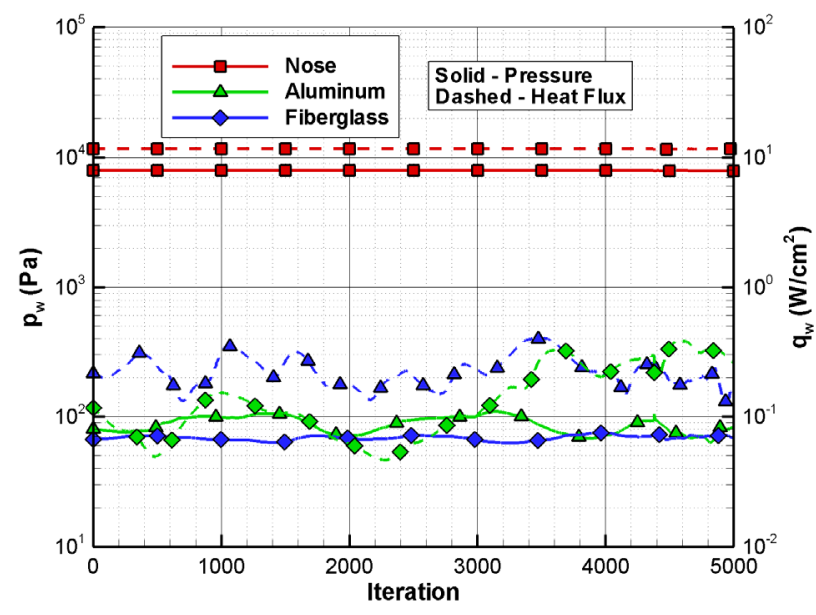

Figure 22. LAURA Pressure and Heat Flux TimeHistories on the Forebody Nose, Aluminum Base Cover, and Fiberglass Base Cover, Using Local TimeStepping on Grid 3 at $\mathbf{t}=\mathbf{1 1 7 1 0 . 5} \mathrm{sec}$

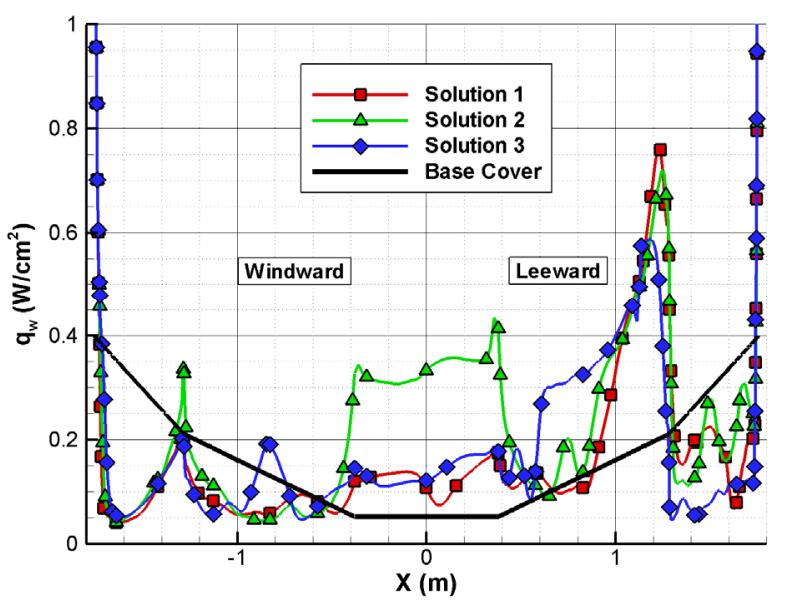

Figure 21. LAURA Afterbody Symmetry Plane Heat Flux at $t=11710.5$ sec for Grid 3 with Local TimeStepping after Successive Adaptations

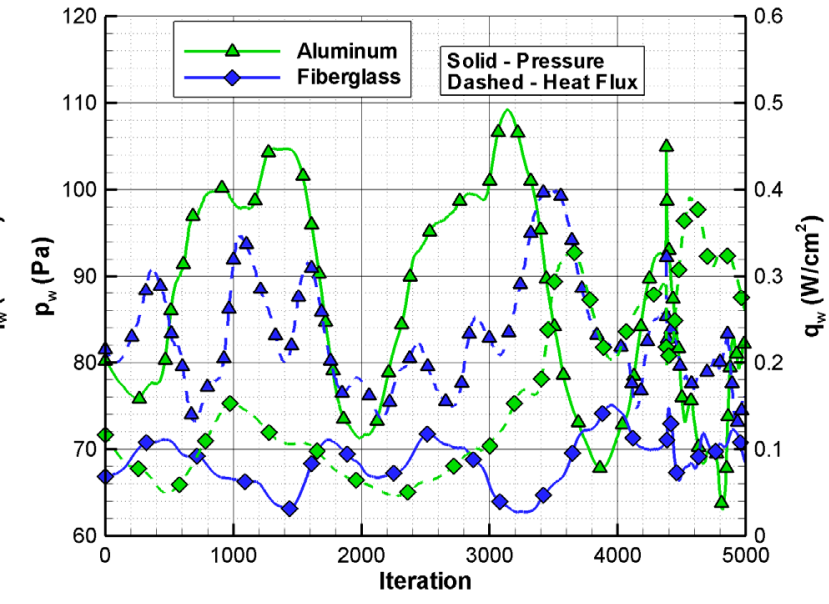

Figure 23. LAURA Base Cover Pressure and Heat Flux Time-Histories Using Local Time-Stepping on Grid 3 at $\mathrm{t}=\mathbf{1 1 7 1 0 . 5} \mathrm{sec}$ 


\section{Effects of Global Time-Stepping}

Reference 36 analysis found that LAURA hypersonic solutions that were difficult to converge to a steady state benefited from using global time-stepping. The region between the Viking shear layer and afterbody surface is subsonic, so computational errors are propagated more easily in that area and could explain the difficulty in obtaining heat flux convergence. The Viking wake flow was almost certainly unsteady to some extent, so using time-accurate solutions was investigated as a method for improving the computational results.

An implicit first-order time-accurate option using 20 sub-iterations was exercised for the LAURA solutions. The solutions were expected to either behave periodically over time or asymptotically approach a steady state heat flux. In the case of a periodically varying heat flux, a time average could be used for comparison to flight data. The solutions using local time-stepping were used as a starting point for the time-accurate results. A total of approximately 10000 iterations were run using a fixed global time step. The time step was chosen to be $5 \%$ of the time it takes the freestream velocity to travel the length of the aeroshell diameter.

The results in Figures 24-27 show that global time-stepping immediately changed the behavior of the afterbody flowfield. Using a fixed time step after approximately 5000 iterations, pressure and heat flux no longer vary as randomly as they do with the local time-stepping. However, neither pressure nor heat flux appears to asymptotically

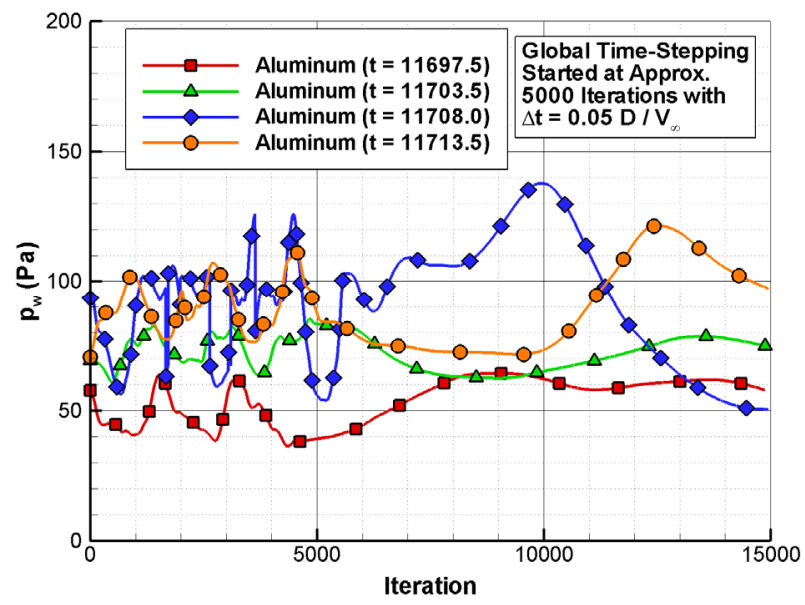

Figure 24. LAURA Aluminum Base Cover Pressure Time-Histories with Local and Global Time-Stepping

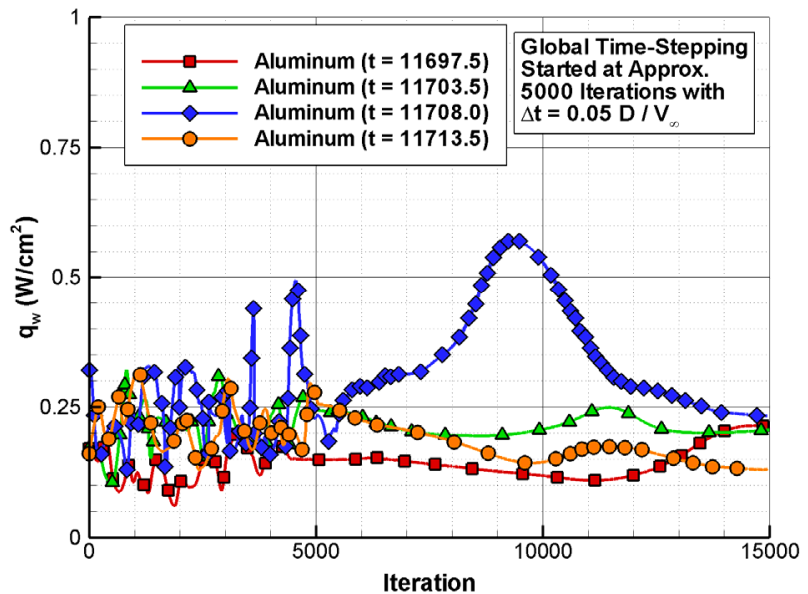

Figure 26. LAURA Aluminum Base Cover Heat Flux Time-Histories with Local and Global Time-Stepping

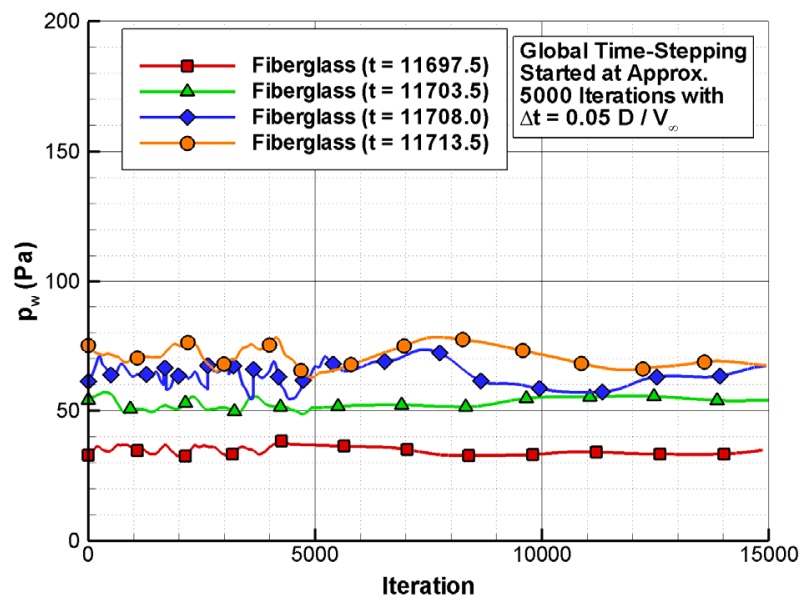

Figure 25. LAURA Fiberglass Base Cover Pressure Time-Histories with Local and Global Time-Stepping

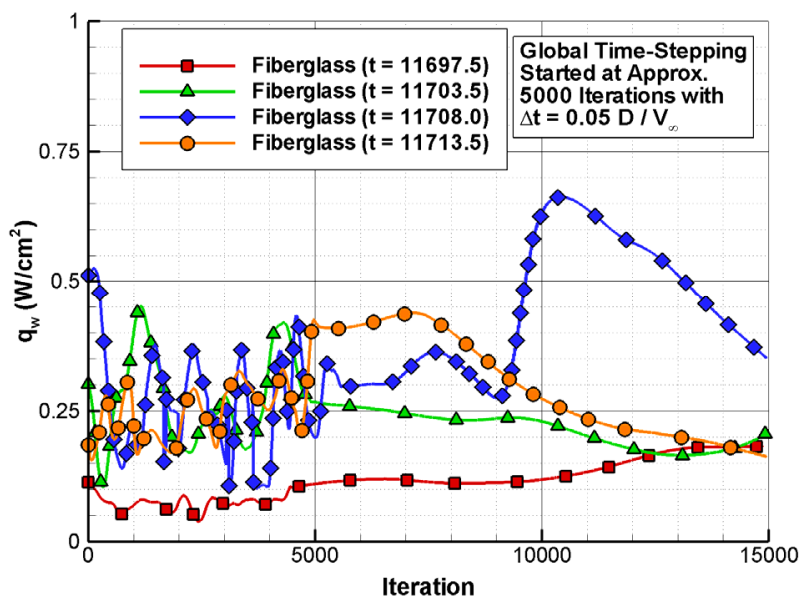

Figure 27. LAURA Fiberglass Base Cover Heat Flux Time-Histories with Local and Global Time-Stepping 
approach fixed values for either location. Both pressure and heat flux on the aluminum base cover continue to vary significantly with global time-stepping, perhaps due to an unsteady shear layer. The fiberglass base cover pressure (Fig. 25) shows the least variation of all results, but the heat flux is much more sensitive during the time of global time-stepping. Periodic behavior is not observed in the flowfield for either base cover location, either because not enough iterations were run or because none exists. Based on the unsteady nature of the flowfield, single-valued CFD heat flux results cannot be reported. Instead, the LAURA results are reported as average, low, and high heat flux over the final 10000 iterations using global time-stepping. The LAURA solutions were obtained on Grid 3, which has the highest streamwise resolution at the shoulder. DPLR solutions were also run on the finest grid using a fixed global time step for approximately 2000 iterations.

\section{Comparison of Viking and Mars Science Laboratory Wake Flowfields}

The approach used here to predict Viking laminar afterbody heating is similar to the one presented in Reference 3 for the MSL entry vehicle. The MSL grid resolution study did not indicate the need for global time-stepping for grid topologies similar to those shown here. Stable and converged afterbody pressure and heat flux were obtained for the MSL geometry using grid resolution similar to that used here. The primary differences between the Viking and MSL analyses are the aeroshell shoulder radius and entry trajectory. The Reynolds numbers are higher on the MSL trajectory due to a higher entry velocity ${ }^{3}$. Figure 28 shows the Viking and MSL aeroshell geometries. The MSL aeroshell shape is simply a $3.75-\mathrm{m}$ diameter version of Viking with a larger shoulder radius.

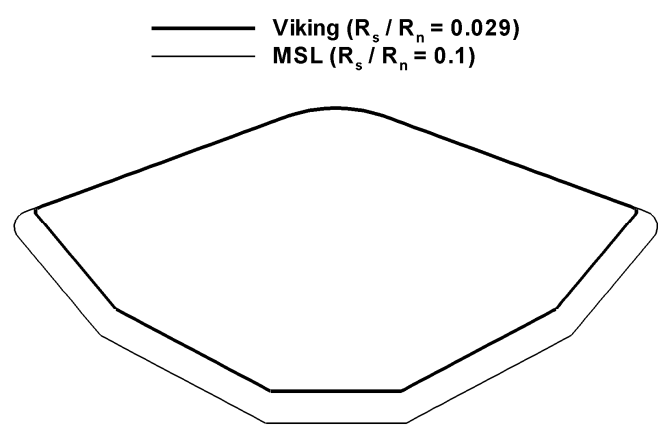

Figure 28. Viking and MSL Aeroshell Shapes

It is the author's belief that the smaller Viking shoulder radius is primarily responsible for the difficulty in modeling the wake flowfield. Figure 29 compares streamlines and normalized velocity contours for the Viking and MSL aeroshells at a Reynolds number near $1.0 \times 10^{6}$ and an angle of attack of about $11 \mathrm{deg}$. The influence of the shoulder radius can be seen in the shear layer angle of departure from the shoulder. For Viking, the leeside shear layer is almost parallel to the body rotational axis. In contrast, the MSL leeside shear layer rotates clockwise from the horizontal and is closer to the afterbody surface. On both the windside and leeside, the region between the shear layer and body surface is larger for Viking than it is for MSL. Viking's larger wake enclosure results in two large vortices on the leeside and smaller vortices on the windside second cone. These types of flowfield structures would not be expected to remain steady and would not lend themselves to a single-valued heat flux computation. The contention is that the larger MSL shoulder radius permits attached flow further rearward on the first afterbody cone,
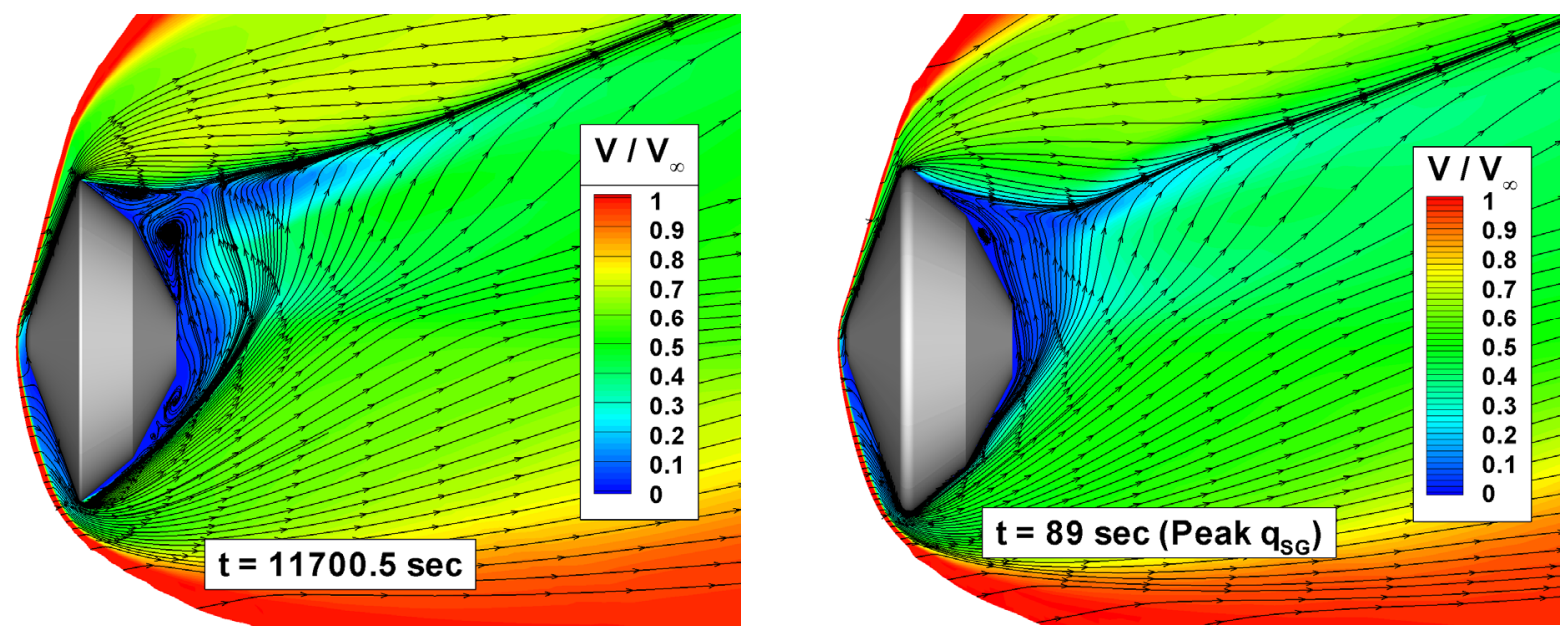

Figure 29. Viking (Left) and MSL (Right from Ref. 3) Symmetry Plane Streamlines and Normalized Velocity Contours at $\alpha \approx 11 \mathrm{deg}$ and $\operatorname{Re}_{\mathrm{D}} \approx 1.0 \times 10^{6}$ 
resulting in a narrower wake enclosure and no large vortices between the shear layer and body surface. Viking's sharp shoulder radius causes earlier flow separation and a larger wake enclosure populated with multiple vortices. Using local time-stepping with an unsteady flowfield is not a well posed problem. Global time-stepping is shown to remove noise in the Viking solutions, but not produce a converged steady state flowfield.

\section{Laminar CFD Comparisons to Heat Flux Data}

Time-accurate heat flux solutions were compared to the flight data. The CFD results are reported as average, low, and high heat flux using global time-stepping. This process was employed only after the forebody solution had converged. All forebody solutions were grid converged and grid independent. That is, the forebody surface quantities e. g. pressure and heat flux, did not change significantly after successive grid adaptations.

Comparisons between the CFD base cover heat flux computations and values derived from the flight data are shown in Figures 30 and 31. The three data curves represent the nominal, low, and high estimates of heat flux as derived from temperature data and including uncertainties. Both CFD codes give heat flux that is lower than the aluminum data indicate (Fig. 30). The LAURA results are below even the lowest heat flux estimate from the temperature data. DPLR gives somewhat higher heat flux, but at most it is equal to the lowest flight data estimate (at $11691.5 \mathrm{sec}$ ). LAURA gives a heat pulse that is somewhat more random than the DPLR heat pulse. A drop in DPLR heat flux at $11703.5 \mathrm{sec}$ occurs for unknown reasons and demonstrates the difficulty in interpreting the results. The highest heat flux from the LAURA solutions occurs at $11708 \mathrm{sec}$, which is the time of peak dynamic pressure. This result agrees with previous analysis showing that afterbody heat flux mirrors dynamic pressure. The spread in the CFD heat flux values is larger for later times (and higher $\mathrm{Re}_{\mathrm{D}}$ ). In fact, the difference between the low and high CFD values is a large fraction of the average for some times. LAURA average heat flux is $60-80 \%$ lower than the nominal data. The difference between DPLR average heat flux and the nominal data is $40-60 \%$.

The same results are shown for the fiberglass base cover in Figure 31. The CFD heat flux results exhibit unsteady behavior similar to the aluminum base cover results. Neither code predicts a smoothly varying heat pulse like the data. The LAURA average heat flux fluctuates more than the DPLR average. LAURA predicts the highest heat flux to occur at peak dynamic pressure $(11708 \mathrm{sec}$.). However, the CFD results possess too much scatter to draw any further conclusions. LAURA average heat flux is $20-75 \%$ lower than the nominal data. The difference between DPLR average heat flux and the nominal data is $30-65 \%$. Both codes predict high heat flux values that are bounded by the data for some of the solutions. The fiberglass base cover thermocouple location is in a large subsonic area that would be expected to be even more influenced by unsteady shear layer development. Perhaps that is the reason that the CFD solutions exhibit more scatter than the aluminum base cover results.
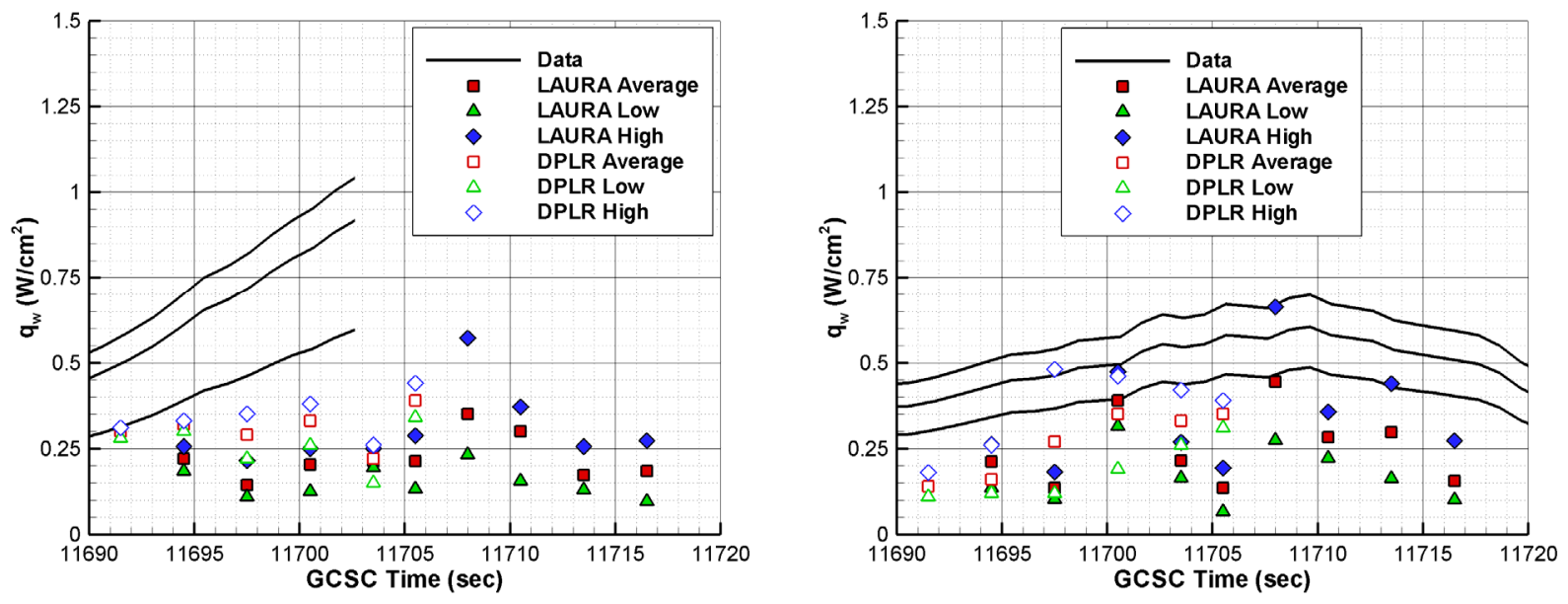

$\begin{aligned} & \text { Figure 30. LAURA and DPLR Aluminum Base Cover Figure 31. LAURA and DPLR Fiberglass Base Cover } \\ & \text { Heat Flux Compared to Flight Data }\end{aligned}$
Heat Flux Compared to Flight Data

There are possible reasons why the heat flux data may be lower than the results shown here. Figure 32 shows the aluminum base cover heat flux data and the relative contributions of the terms in Equation 2. Conduction effects 
are not included in the nominal heat flux. The same information is plotted for the fiberglass base cover in Figure 33 . The contribution of the $\rho c_{p}$ term to total convective heat flux increases as the heat flux increases for both base cover locations. The $\sigma \varepsilon \mathrm{T}^{4}$ term has a lesser influence on convective heat flux for most of the heat pulse, especially for the aluminum cover. Both the $\rho c_{p}$ and $\sigma \varepsilon T^{4}$ terms would not be expected to have uncertainties much larger than those used here because they are a function of well known material properties. Thus, the RTG internal heat source and conduction terms are considered the only ones that could lead to a significantly lower derived heat flux than is presented here. Figures 32 and 33 show that the RTG heat source contribution is small relative to all other terms $\left(<10 \%\right.$ of peak $\left.\mathrm{q}_{\mathrm{conv}}\right)$, so the uncertainty in that term would have to be much larger in order to have a noticeable effect. As mentioned before, details of the RTG operation during entry were not found. Also, the effects of the RTG location and wind covers are not known. Based on drawings of the aeroshell (Fig. 5), the RTG's are closer to the fiberglass base cover, but the clocking angle relative to the thermocouple is unknown. It is conceivable that local hot spots were present on the base cover due to the close proximity of the RTG units. Nevertheless, the estimated RTG heat output is a small percentage of the total heating, especially near the time of peak heat flux. The author's belief is that the conduction effects, especially for the aluminum base cover, are more likely to be underestimated. However, lack of knowledge about the structural details prevents a more rigorous assessment of conduction effects.
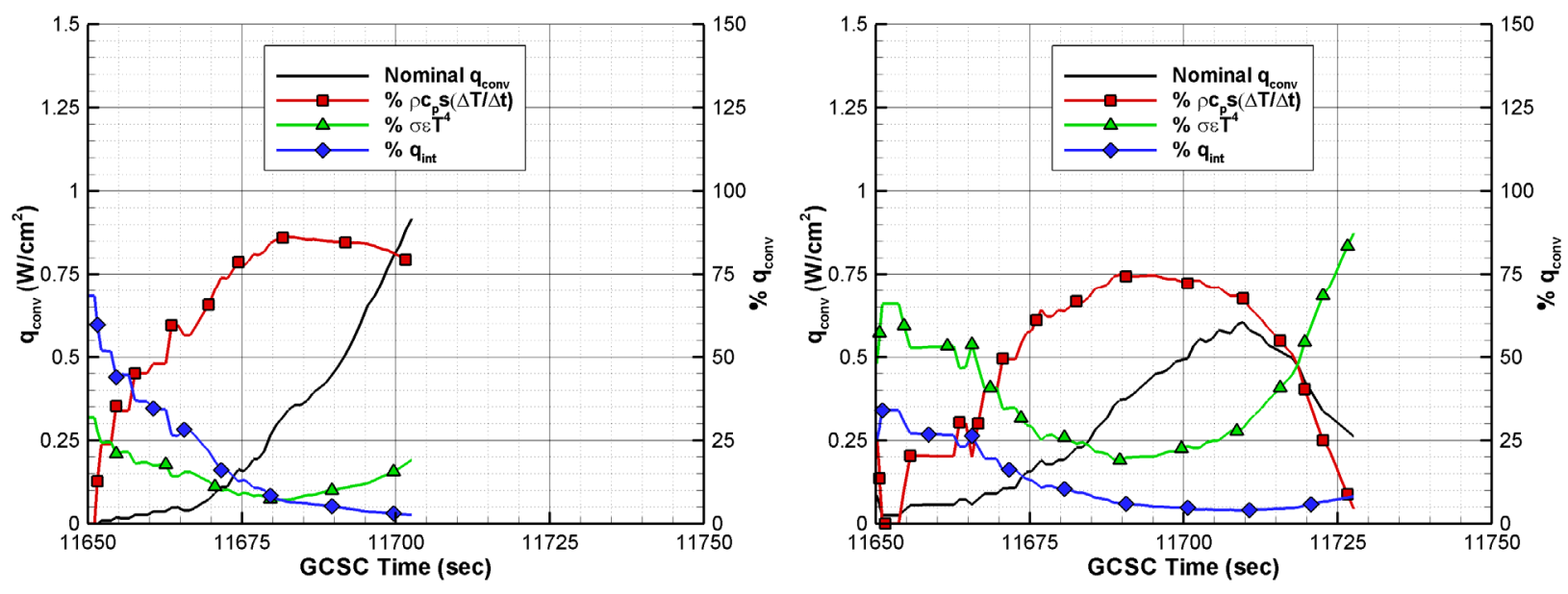

\section{Figure 32. Aluminum Base Cover Nominal Heat Flux Figure 33. Fiberglass Base Cover Nominal Heat Flux Data and Relative Contributions from Equation 2 Data and Relative Contributions from Equation 2}

Improper surface catalysis modeling may explain the low CFD results. See Reference 35 for a discussion of catalysis effects on Mars laminar forebody heating predictions. The primary recombination reactions at the surface are as follows ${ }^{35}$ :

$$
\begin{gathered}
\mathrm{CO}+\mathrm{O} \rightarrow \mathrm{CO}_{2}, \quad \Delta E=5.51 \mathrm{eV} \\
\mathrm{O}+\mathrm{O} \rightarrow \mathrm{O}_{2}, \quad \Delta E=5.16 \mathrm{eV}
\end{gathered}
$$

In flight, these exothermic reactions compete for the $\mathrm{O}$ atoms available for recombination. The mechanisms and sensitivities of these reactions are poorly understood and not easily measured. In practice, the CFD solutions are run with the super-catalytic wall boundary condition, which specifies recombination of $\mathrm{CO}_{2}$ and $\mathrm{N}_{2}$ to their freestream mass fractions at the surface. This boundary condition is enforced regardless of whether the local surface conditions would allow full recombination to occur. In flight, if $\mathrm{CO}$ and $\mathrm{O}$ do not fully recombine on the forebody surface, those species could be carried into the wake flowfield where the residence times are much longer. Given more time, the $\mathrm{CO}$ and $\mathrm{O}$ would be more likely to recombine at the afterbody surface and result in augmented heating. The CFD solutions do not allow excess $\mathrm{CO}$ and $\mathrm{O}$ to reach the afterbody, so the potential afterbody heating augmentation cannot be realized. Thus, improper modeling of surface catalytic reactions could lead to low CFD afterbody heating results. The magnitude of this catalytic effect on afterbody heat flux is unknown. 
It is possible that improvements in the grid topology and shear layer resolution would improve solution convergence. Currently, LAURA and DPLR adapt the surface-normal grid cells to the boundary layer and bow shock. Automatic clustering at a free shear layer was not employed in the current analysis. The addition of this capability should be examined for its effect on solution stability with local and global time-stepping. Improved resolution of the shear layer could lead to more accurate results in the region between the shear layer and surface, where much of the unsteadiness originates. However, improvements in the grid topology and adaptation will not eliminate inherent flowfield unsteadiness.

It is important to note that even though the CFD predictions for the two base cover locations are low compared to the data, this does not necessarily mean that CFD would result in low heating predictions for an actual TPS design. Figure 34 shows a contour plot of heat flux from the LAURA solution at $11710.5 \mathrm{sec}$. The maximum heat flux does not occur at either of the thermocouple locations, but rather at two other locations. In fact, the heat flux on the entire base cover varies by an order of magnitude. One of the hot spots is close to the aluminum base cover thermocouple. It is conceivable that even a small yaw angle could move the hot spot directly onto the aluminum base cover thermocouple location. This would result in a heat flux increase of more than $100 \%$ over the value reported with zero yaw angle. The CFD results at $11708 \mathrm{sec}$ (Fig. 26 and 27) suggest that a hot spot may have moved over both thermocouple locations during the time-accurate solution process. The flight data indicate a yaw angle near 1 deg throughout entry ${ }^{1}$. Full three-

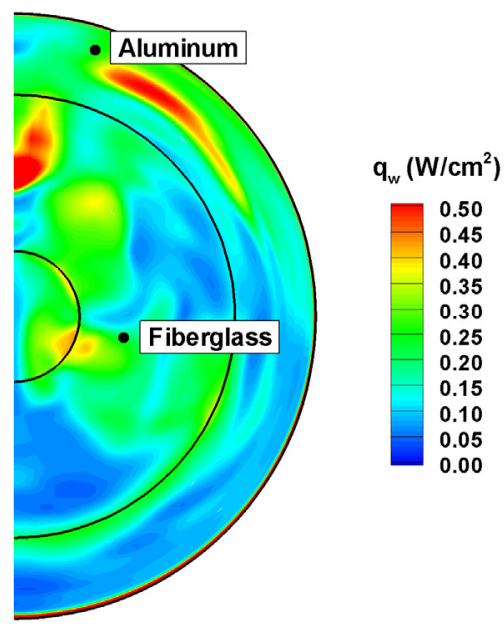

Figure 34. LAURA Base Cover Heat Flux at $t=$ 11710.5 sec After 10000 Iterations with Global TimeStepping dimensional CFD solutions with a non-zero yaw angle are recommended to examine the effects on heat flux.

In the design process, the maximum heat flux on the entire afterbody would be identified as the limiting value. Plus, an additional uncertainty would be added to an already conservative estimate. Afterbody heating uncertainties are typically much larger due in part to the difficulties illuminated here. If the afterbody is considered to be unsteady for a future entry vehicle design, time-accurate CFD solutions should be run to determine the maximum heat flux over a given time period, similar to the process that was presented here.

All CFD cases shown here were run assuming laminar conditions. Although the data is inconclusive, the wake flowfield may have been turbulent at the time of peak stagnation point heating. If the wake flowfield was turbulent, the shear layer structure could be significantly altered and the heat flux may be augmented. In that case, computational methods for obtaining turbulent solutions should be investigated. LAURA and DPLR have several turbulence model options available, however their applicability to wake flowfields is questionable. Methods other than Navier-Stokes solvers may be better suited to predict massively separated turbulent flowfields. One method which has shown promise is Detached Eddy Simulation (DES) ${ }^{37}$. The DES method is designed for an unsteady flowfield at high Reynolds number conditions, where turbulence is more likely. The development of the DES method is recent and its use for hypersonic blunt-body wake flowfields would be a good test of its capabilities.

Given the discrepancies between Viking flight data and Navier-Stokes CFD methods, continued improvements in the computational tools and their application are needed before large reductions in afterbody heat flux uncertainties can be realized. The amount of relevant afterbody heat flux data is sparse, especially at Mars entry conditions. The only other flight data that exists for a Mars entry is from Pathfinder ${ }^{4}$. Unfortunately, two of the three afterbody thermocouples failed during entry ${ }^{38}$. A comparison between CFD methods and the remaining thermocouple data is recommended. Finally, additional ground testing with flight-relevant conditions is recommended for code validation. The continued comparison of CFD methods with relevant ground and flight data is the best method for developing and validating the computational tools for afterbody heating prediction. 


\section{Summary and Conclusions}

Computational fluid dynamics solutions of the Viking Lander 1 entry vehicle flowfield were obtained to compare afterbody heat flux predictions to flight data. Temperature data at two locations on the entry aeroshell base cover were converted to convective heat flux using the one-dimensional heat balance equation. The heat flux derivation includes uncertainties for material response, internal heats sources, and conduction effects. The heat flux at the aluminum base cover thermocouple was derived to be $0.63-1.10 \mathrm{~W} / \mathrm{cm}^{2}$ at the time the sensor failed, with a nominal value of $0.97 \mathrm{~W} / \mathrm{cm}^{2}$. Peak heat flux for the fiberglass base cover was derived to be $0.54-0.76 \mathrm{~W} / \mathrm{cm}^{2}$, with a nominal value of $0.66 \mathrm{~W} / \mathrm{cm}^{2}$. Peak fiberglass heating occurred $16 \mathrm{sec}$ after peak stagnation point heat flux and $2.5 \mathrm{sec}$ after peak dynamic pressure. The heat pulses for both thermocouples mirror the freestream dynamic pressure and lag behind the stagnation point heat pulse.

Navier-Stokes solutions of the wake flowfield were obtained with the LAURA and DPLR CFD codes using finite-rate chemistry, radiative-equilibrium wall temperature, and full surface recombination of $\mathrm{CO}_{2}$ and $\mathrm{N}_{2}$. The original LTARP post-flight trajectory analysis was used to define freestream conditions as a function of time. LAURA solutions did not yield steady state wake flowfields using local time-stepping. The belief is that the small Viking shoulder radius does not permit attached flow beyond the aeroshell maximum diameter, leading to multiple unsteady vortices between the shear layer and afterbody surface. Time-accurate solutions with global time-stepping improved computational stability, but the heat flux did not approach a fixed steady state. Both CFD codes predict unsteady flow at each base cover location as determined from time-histories of pressure and heat flux. The conclusion is that the wake flowfield is unsteady to the extent that steady state CFD results cannot be reported.

An approach was used to average the CFD base cover heat flux using the time-accurate results. Both LAURA and DPLR give average base cover heat fluxes that are generally far below the flight data. The CFD heat flux is 40$80 \%$ below the nominal aluminum base cover data and $20-75 \%$ below the nominal fiberglass data. A large amount of scatter in the CFD results makes it difficult to make concrete conclusions about using modern methods for afterbody heating and indicates the difficulty in computing wake flowfields. Possible reasons for the mismatch between CFD and the data include underestimated conduction effects, improper surface catalycity modeling, and other limitations of the computational methods. The effects of non-zero yaw angle were not included and should be examined with CFD. Improved computational solutions may be possible with more advanced grid topologies that allow adaptation to the afterbody shear layer. Other computational methods, such as Detached Eddy Simulation, may be better suited to computing a massively-separated wake flowfield that is unsteady and possibly turbulent. The continued use of conservative afterbody heat flux uncertainties is recommended for future Mars entry vehicles pending improvements in the computational methods and additional validation efforts.

\section{Acknowledgments}

The authors would like to thank Durwin Schmitt for providing printouts of Viking base cover temperature data and background information on his analysis presented in Reference 2.

\section{References}

\footnotetext{
${ }^{1}$ Ingoldby, R. N., Michel, F. C., Flaherty, T. M., Doryand, M. G., Preston, B., Villyard, K. W., and Steele, R. D., "Entry Data Analysis for Viking Landers 1 and 2 Final Report," NASA CR-159388, Martin Marietta Corporation, Nov. 1976.

2 Schmitt, D. A., "Base Heating on an Aerobraking Orbital Transfer Vehicle," AIAA Paper 83-0408, AIAA Aerospace Sciences Meeting and Exhibit, Reno, NV, Jan. 1983.

3 Edquist, K. T., "Afterbody Heating Predictions for a Mars Science Laboratory Entry Vehicle," AIAA Paper 2005-4817, AIAA Thermophysics Conference, Toronto, Ontario, Canada, June 2005.

${ }^{4}$ Wright, M. J., Milos, F. S., and Tran, P., "Survey of Afterbody Aeroheating Flight Data for Planetary Probe Thermal Protection System Design," AIAA Paper 2005-4815, AIAA Thermophysics Conference, Toronto, Ontario, Canada, June 2005.

${ }^{5}$ Lockwood, M. K., Powell, R. W., Graves, C. A., and Carman, G. L., "Entry System Design Considerations for Mars Landers," AAS 01-023, AAS Guidance and Control Conference, Breckenridge, CO, Jan.-Feb. 2001.

${ }^{6}$ Cooley, C. G., and Lewis, J. G., "Viking 75 Project: Viking Lander System Primary Mission Performance Report," NASA CR-145148, Martin Marietta Corporation, Apr. 1977.

${ }^{7}$ Schmitt, D. A., Private Communication, Apr. 2005.
} 
${ }^{8}$ Viking Flight Team Memorandum LS0-17290-TMF, "Viking 1 Entry Heating of Basecover and Aeroshell, Results and Prediction for Viking 2," Aug. 1976.

9 Marvin, J. G., and Akin, C. M.,'Pressure and Convective Heat Transfer Measurements in a Shock Tunnel Using Several Test Gases," NASA TND-3017, 1965.

${ }^{10}$ MatWeb Material Property Data, http://www.matweb.com, copyright 1996-2005 by Automation Creations, Inc.

${ }^{11}$ Morey, T. F., and Gorman, D. N., "Development of the Viking Mars Landers Thermal Control Subsystem Design," AIAA Paper 74-759, AIAA/ASME Thermophysics and Heat Transfer Conference, Boston, MA, Jul. 1974.

${ }^{12}$ Seiff, A., and Kirk, D. B., "Structure of the Atmosphere of Mars in Summer at Mid-Latitudes," Journal of Geophysical Research, Vol. 82, No. 28, 30 Sept. 1977, pp. 4364-4378.

${ }^{13}$ Blanchard, R. C., and Walberg, G. D., "Determination of the Hypersonic-Continuum/Rarefied-Flow Drag Coefficient of the Viking Lander Capsule 1 Aeroshell from Flight Data," NASA TP 1793, Dec. 1980.

${ }^{14}$ Seiff, A., "Atmosphere Temperature and Pressure Listings on Microfiche," http://nssdc.gsfc.nasa.gov/nmc/tmp/PSPA00269-personnel.html, NSSDCID: PSPA-00269, National Space Science Data Center.

${ }^{15}$ Holmberg, N. A., Faust, R. P., and Holt, H. M., "Viking '75 Spacecraft Design and Test Summary, Volume 1 - Lander Design," NASA RP 1027, Nov. 1980.

${ }^{16}$ Cooley, C. G., and Lewis, J. G., "Viking 75 Project, Viking Lander System Primary Mission Performance Report," NASA CR 145148, Apr. 1977.

${ }^{17}$ Kirk, D. B., Intrieri, P. F., and Seiff, A., "Aerodynamic Behavior of the Viking Entry Vehicle: Ground Test and Flight Results," Journal of Spacecraft, Vol. 15, No. 4, Jul.-Aug. 1978.

${ }^{18}$ Hopper, F. W., Parsons, C. C., Davidson, D. L., Beacon, J. A., and Gillogly, R., "Viking 75 Project: Lander Trajectory and Atmospheric Reconstruction Program (LTARP) User's Guide," SD-3700005 Rev. A, Martin Marietta Corporation, Dec., 1974.

${ }^{19}$ Allen, Jr., Gary A., Wright, Michael J., and Gage, Peter, “The Trajectory Program (TRAJ): Reference Manual and User's Guide," NASA TM 2005-212847, Mar. 2005.

${ }^{20}$ Sutton, K. and Graves, R. A., "A General Stagnation-Point Convective-Heating Equation for Arbitrary Gas Mixtures," NASA TR R-376, Nov. 1971.

${ }^{21}$ Cheatwood, F. M. and Gnoffo, P. A., "User's Manual for the Langley Aerothermodynamic Upwind Algorithm (LAURA)," NASA TM-4674, Apr. 1996.

${ }^{22}$ Wright, M. J., Candler, G. V., and Bose, D., "Data-Parallel Line Relaxation Method for the Navier-Stokes Equations," AIAA Journal, Vol. 36, No. 9, 1998, pp. 1603-1609.

${ }^{23}$ Wright, M. J., Olejniczak, J., Brown, J. L., Hornung, H. G., and Edquist, K. T.," Computational Modeling of T5 Laminar and Turbulent Heating Data on Blunt Cones, Part 2: Mars Applications," AIAA Paper 2005-0177, AIAA Aerospace Sciences Meeting and Exhibit, Reno, NV, Jan. 2005.

${ }^{24}$ Papadopoulos, P., Prahbu, D., Olynick, D., Chen, Y. K., and Cheatwood, F. M., "CFD Code Validation and Comparisons for Mars Entry Simulations,” AIAA Paper 98-0272, AIAA Aerospace Sciences Meeting \& Exhibit, Reno, NV, Jan. 1998.

${ }^{25}$ Queen, E. M., Cheatwood, F. M., Powell, R. W., Braun, R. D., and Edquist, C. T.: "Mars Polar Lander Aerothermodynamic and Entry Dispersion Analysis,' Journal of Spacecraft and Rockets, Vol. 36, No. 3, May-June 1999.

${ }^{26}$ Edquist, K. T, "Afterbody Heating Predictions for a Mars Science Laboratory Entry Vehicle," AIAA Paper 2005-4817, AIAA Thermophysics Conference, Toronto, Ontario, Canada, June 2005.

${ }^{27}$ Park, C., Howe, J. T., Jaffe, R. L., and Candler, G. V., "Review of Chemical-Kinetic Problems of Future NASA Missions, II: Mars Entries," Journal of Thermophysics and Heat Transfer, Vol. 8, No.1, Jan.-Mar. 1994.

${ }^{28}$ Roe, P. L., “Approximate Reimann Solvers, Parameter Vectors and Difference Schemes," Journal of Computational Physics, Vol. 43, No. 2, 1981.

${ }^{29}$ Yee, H. C., "On Symmetric and TVD Upwind Schemes," NASA TM-86842, Sept. 1985.

${ }^{30}$ Steinbrenner, J. P. and Chawner, J., "Gridgen's Implementation of Partial Differential Equation Based Structured Grid Generation Methods", Proceedings, 8th International Meshing Roundtable, South Lake Tahoe, CA, Oct. 1999.

${ }^{31}$ MacCormack, R. W. and Candler, G. V., "The Solution of the Navier-Stokes Equations Using Gauss-Seidel Line Relaxation," Computers and Fluids, Vol. 17, No. 1, 1989, pp. 135-150.

${ }^{32}$ Yee, H. C., "A Class of High-Resolution Explicit and Implicit Shock Capturing Methods," NASA TM 101088, Feb. 1989.

${ }^{33}$ Wright, M. J., Loomis, M. A., and Papadopoulos, P. E., "Aerothermal Analysis of the Project Fire II Afterbody Flow," Journal of Thermophysics and Heat Transfer, Vol. 17, No. 2, 2003, pp. 240-249.

${ }^{34}$ Wright, M. J., Prabhu, D. K., and Martinez, E. R., "Analysis of Afterbody Heating Rates on the Apollo Command Module, Part 1: AS-202," AIAA Paper No. 2004-2456, AIAA Thermophysics Conference, Portland, OR, June 2004.

${ }^{35}$ Bose, D., Wright, M. J., and Palmer, G. E., "Uncertainty Analysis of Laminar Aeroheating Predictions for Mars Entries," AIAA Paper 2005-4682, AIAA Thermophysics Conference, Toronto, Ontario, Canada, June, 2005.

${ }^{36}$ Gnoffo, P. A., "On the Numerical Convergence to Steady State of Hypersonic Flows Over Bodies with Concavities," West East High Speed Flow Field Conference, Marseille, France, Apr. 2002.

${ }^{37}$ Strelets, "Detached Eddy Simulation of Massively Separated Flows," AIAA Paper 2001-0879, AIAA Aerospace Sciences Meeting and Exhibit, Reno, NV, Jan. 2001.

${ }^{38}$ Milos, F. S., Chen, Y.-K., Congdon, W. M., and Thornton, J. M., "Mars Pathfinder Entry Temperature Data, Aerothermal Heating, and Heatshield Material Response," Journal of Spacecraft and Rockets, Vol. 36, No. 3, May-June 1999. 